\title{
Alterations of gene expression and protein synthesis in co-cultured adipose tissue-derived stem cells and squamous cell-carcinoma cells: consequences for clinical applications
}

\author{
Eva Koellensperger ${ }^{1 *}$, Felix Gramley², Fabian Preisner ${ }^{1}$, Uwe Leimer ${ }^{1}$, Guenter Germann ${ }^{1}$ and Verena Dexheimer ${ }^{1}$
}

\begin{abstract}
Introduction: This is the first study evaluating the interactions of human adipose tissue derived stem cells (ADSCs) and human squamous cell carcinoma cells (SCCS), with regard to a prospective cell-based skin regenerative therapy and a thereby unintended co-localization of ADSCs and SCCs.

Methods: ADSCs were co-cultured with A431-SCCs and primary SCCs (pSCCs) in a transwell system, and cell-cell interactions were analyzed by assessing doubling time, migration and invasion, angiogenesis, quantitative real time PCR of 229 tumor associated genes, and multiplex protein assays of 20 chemokines and growth factors and eight matrix metalloproteinases (MMPS). Results of co-culture were compared to those of the respective mono-culture.

Results: ADSCs' proliferation on the plate was significantly increased when co-cultured with A431-SCCS $(P=0.038)$. PSCCS and ADSCs significantly decreased their proliferation in co-culture if cultured on the plate $(P<0.001$ and $P=0.03)$. The migration of pSCC was significantly increased in co-culture $(P=0.009)$, as well as that of ADSCs in A431-SCC-Co-culture $(P=0.012)$. The invasive behavior of pSCCs and A431-SCCs was significantly increased in co-culture by a mean of $33 \%$ and $35 \%$, respectively ( $P=0.038$ and $P<0.001)$. Furthermore, conditioned media from co-cultured ADSC-A431-SCCs and co-cultured ADSCs-pSCCs induced tube formation in an angiogenesis assay in vitro.

In A431-SCC-CO-culture 36 genes were up- and 6 were down-regulated in ADSCs, in A431-SCCs 14 genes were up- and 8 genes were down-regulated. In pSCCs-Co-culture 36 genes were up-regulated in ADSCs, two were down-regulated, one gene was up-regulated in PSCC, and three genes were down-regulated. Protein expression analysis revealed that three proteins were exclusively produced in co-culture (CXCL9, IL-1b, and MMP-7). In A431-SCC-co-culture the concentration of 17 proteins was significantly increased compared to the ADSCs mono-culture (2.8- to 357-fold), and 15 proteins were expressed more highly (2.8- to 1,527-fold) compared to the A431-SCCs mono-culture. In pSCC-co-culture the concentration of 10 proteins was increased compared to ADSCs-mono-culture (2.5- to 77-fold) and that of 15 proteins was increased compared to pSCC mono-culture (2.6- to 480-fold).
\end{abstract}

Conclusions: This is the first study evaluating the possible interactions of primary human ADSCs with human SCCs, pointing towards a doubtlessly increased oncological risk, which should not be neglected when considering a clinical use of isolated human ADSCs in skin regenerative therapies.

\footnotetext{
* Correspondence: eva.koellensperger@ethianum.de

${ }^{1}$ Clinic for Plastic and Reconstructive Surgery, Aesthetic and Preventive

Medicine at Heidelberg University Hospital - ETHIANUM, Voßstraße 6, 69115

Heidelberg, Germany

Full list of author information is available at the end of the article
}

\section{Ciomed Central}

(c) 2014 Koellensperger et al.; licensee BioMed Central Ltd. This is an Open Access article distributed under the terms of the Creative Commons Attribution License (http://creativecommons.org/licenses/by/2.0), which permits unrestricted use, distribution, and reproduction in any medium, provided the original work is properly credited. 


\section{Introduction}

Skin therapies based on adipose tissue derived stem cells (ADSCs) are becoming more and more attractive, regarding the possible positive effects of mesenchymal stem cells on skin cells, such as an increase in collagen content, an improvement of nutrition by increased angiogenesis, a "whitening" effect through inhibition of tyrosine kinase effect, a reduced apoptosis and a UV-protection of dermal fibroblasts [1-5]. ADSCs have been shown to secrete various growth factors that transmit these effects through a paracrine fashion. This mechanism, however, allows ADSCs to interact with tumor cells, too $[6,7]$. Cancer-associated fibroblasts (CAFs) have been shown to be a crucial component in tumor cell proliferation, cancer invasion and progression by secreting various growth factors, cytokines and proteases into the tumor microenvironment [8]. Since the origin of CAFs is discussed controversially and bone marrow-derived mesenchymal stem cells have also been suggested to be a potential source of CFAs, the question arises of what would happen if ADSCs were injected within the vicinity of local tumor cells, such as skin tumor cells. While one would avoid purposefully injecting ADSCs in a visible skin tumor, of course, an unintended injection of ADSC adjacent to subclinical skin tumor cells is conceivable.

The squamous cell carcinoma is the second-most common skin tumor with a rising incidence of 25/100,000 people in Europe at the moment [9]. So far squamous cell carcinoma cells (SCCs) have not yet been analyzed in this context. Considering the rising use of fat and stem cellenriched fat as well as the proposed use of isolated ADSCs, for example, in skin regenerative therapies, it is necessary to analyze the possible interactions of human ADSC with human squamous cell carcinoma cells.

To gain further insight in respect to such interactions, we co-cultured primary human ADSCs and primary SCCs or A431-SCCs cells. We then analyzed the proteins secreted in their shared media, quantified the changes in proliferation, migration, invasion, angiogenesis and the gene expression of each cell type and compared each of the results to that of a mono-culture of the same cell type.

\section{Methods}

All chemicals, if not noted separately, were purchased from Sigma-Aldrich, Munich, Germany.

\section{Donor specification}

This study was conducted under the guidelines and with the approval of the ethical committees of the University of Heidelberg and of the medical association of the local district of Baden-Wuerttemberg, Germany. After the authors received informed consent, freshly excised subcutaneous adipose tissue of six women with an age-range of 24 to 48 years (median age 37.5 years) undergoing elective plastic surgery was used for isolation of ADSCs.

\section{ADSCs isolation and culture Isolation of ADSCS}

ADSCs were isolated from freshly excised subcutaneous adipose tissue or liposuction using a procedure modified from Hauner et al. [10]. In brief, the adipose tissue was washed in $1 \%$ bovine serum albumin (BSA)/phosphatebuffered saline (PBS), minced and digested enzymatically by collagenase (collagenase CLS; $220 \mathrm{U} / \mathrm{mg}$, Biochrom AG, Berlin, Germany, $1.5 \mathrm{mg} / \mathrm{ml}$, in $1 \%$ BSA/KrebsRinger-solution) for 45 minutes under constant shaking at $37^{\circ} \mathrm{C}$. Mature adipocytes and connective tissue was separated by centrifugation $(700 \times \mathrm{g}$, seven minutes at room temperature). The sedimented cells were resuspended, passed through a $100 \mu \mathrm{m}$ mesh filter (Neolab, Heidelberg, Germany) and washed twice with $1 \%$ BSA/ PBS. After erythrocyte lysis (three minutes, $155 \mathrm{mM}$ ammoniumchloride, $10 \mathrm{mM}$ potassium bicarbonate, $0.1 \mathrm{mM}$ EDTA) cells were washed again twice and plated at a density of $2 \times 10^{4}$ cells $/ \mathrm{cm}^{2}$ in an expansion medium (see below). After 24 hours the medium was changed to remove non-adhered cells.

\section{Expansion of ADSCs}

ADSCs were cultivated in an expansion medium consisting of $60 \%$ Dulbecco's modified Eagle's medium (DMEM) low glucose (1 g/l D-glucose) (Invitrogen, Life Technologies, Darmstadt, Germany), 40\% MCDB-201, $1 \times$ ITS (insulin transferrin selenous acid) (Becton Dickinson, Heidelberg, Germany), $10^{-8} \mathrm{M}$ dexamethasone, $0.1 \mathrm{mM}$ ascorbic acid-2-phosphate, $2 \%$ fetal calf serum (FCS) (Biochrom), $100 \mathrm{U} / \mathrm{ml}$ penicillin (Biochrom), $0.1 \mathrm{mg} / \mathrm{ml}$ streptomycin (Biochrom), $10 \mathrm{ng} / \mathrm{ml} \mathrm{rhEGF}$ and $10 \mathrm{ng} / \mathrm{ml} \mathrm{rhPDGF}-\mathrm{BB}$ (CellSystems, Troisdorf, Germany). The medium was changed every other day. Once the cells reached $70 \%$ confluence they were detached with $0.25 \%$ trypsin-EDTA (Biochrom) and replated with $3.5 \times 10^{3}$ cells per $\mathrm{cm}^{2}$. ADSCs were incubated at $37^{\circ} \mathrm{C}$ with $5 \% \mathrm{CO}_{2}$ and cultured to passage four.

\section{Determination of ADSCs stemness}

\section{Adipogenic differentiation and oil red staining}

ADSCs were seeded in expansion medium at a density of 24,000 cells $/ \mathrm{cm}^{2}$. After reaching $90 \%$ confluence, adipogenesis was induced by the alternated use of basal medium (10\% FCS/DMEM) supplemented with IDImix (500 $\mu \mathrm{M}$ 3-isobutyl-1-methylxanthine; $1 \mu \mathrm{M}$ dexamethasone; $1 \mu \mathrm{M}$ indomethacin) for two days followed by basal medium plus $10 \mu \mathrm{g} / \mathrm{ml}$ insulin for one day. The induction cycle was repeated three times. To confirm the successful adipogenic differentiation, cytoplasmic 
triglyceride lipid droplets were stained with the Oil Red $\mathrm{O}$ staining method as described previously [11].

\section{Osteogenic differentiation and alizarin red staining}

After seeding with a density of $24,000 \mathrm{ADSC} / \mathrm{cm}^{2}$, cells were grown in expansion medium to $90 \%$ confluence. Osteogenic induction was initiated by changing the medium to DMEM containing 10\% FCS, supplemented with $50 \mu \mathrm{M}$ L-ascorbate-2-phosphate, $0.1 \mu \mathrm{M}$ dexamethasone and $10 \mathrm{mM} \beta$-glycerophosphate disodium salt. On Day 42 calcium deposition was demonstrated histochemically by alizarin red staining as follows: monolayers of mineralized mesenchymal stem cells were washed twice with excess PBS and fixed with pre-chilled $70 \%$ ethanol for one hour at $-20^{\circ} \mathrm{C}$. After a short washing step with $\mathrm{H}_{2} \mathrm{O}$, the cell layer was incubated with $40 \mathrm{mM}$ alizarin red $(\mathrm{pH} 4.2)$ for one minute at room temperature. After aspiration of unincorporated dye, cells were washed twice with $\mathrm{H}_{2} \mathrm{O}$ and once with PBS before microscopic analysis.

\section{Flow cytometry}

ADSCs expanded to passage four were examined for surface marker expression using flow cytometry. The following monoclonal antibodies conjugated to fluorochromes were used: anti-CD13-APC, anti-CD29-PE, anti-CD31-FITC, anti-CD34-FITC, anti-CD44-APC, anti-CD45-FITC, antiCD49a-PE, anti-CD63-FITC,-anti-CD73-PE, anti-CD90-APC, anti-CD105-FITC, anti-CD106-APC and anti-CD-166PE (all from Becton Dickinson, Heidelberg, Germany). Isotype antibodies were included for all fluorochromes.

Cells were detached with $0.25 \%$ trypsin-EDTA, incubated with directly conjugated MAbs in FACS-buffer (1\% FCS, $0.1 \% \mathrm{NaN}_{3}$ in PBS) for 30 minutes on ice, washed twice with FACS buffer, and fixed with $1 \%$ paraformaldehyde/PBS. Cells were analyzed using a FACSCanto flow cytometry system (Becton Dickinson). Data acquisition was performed with Diva software (Becton Dickinson) and data were analyzed using FCS express V3 (De Novo Software).

\section{ADSC-SCC-co-culture}

A431-SCCs were purchased from American Type Culture Collection (ATCC), Manassas, VA, USA, Catalog nr. CRL1555. Primary SCCs from three different donors (two males, one female, median age 50 years) were purchased from Celprogen, San Pedro, CA, USA (Catalog nr. 3612810). The primary SCCs were pooled initially, cultured for two passages and then applied to the co-culture system. Co-culture of tumor cells and ADSCs was performed in a transwell system. For that either $2 \times 10^{4}$ SCCs or $2 \times$ $10^{4}$ ADSCs were seeded onto a polyester membrane transwell-clear insert (Corning, pore size $0.4 \mu \mathrm{m}$ ) while the corresponding other cell type was seeded onto the bottom of a six-well cell culture plate in the same cell density. Cells were cultured up to five days in $4 \mathrm{ml}$ expansion medium per well without medium change. Each day cell culture supernatants were harvested and the cell number was determined after trypzinization and trypan blue staining. SCCs as well as ADSCs alone - either in transwell inserts or on six-well culture plates - served as controls and were treated like the co-culture. For further analysis the exponential growth phase of the cells was determined and the supernatants of Day 4 were analyzed in a protein assay (human cytokine magnetic 30-Plex panel) while the corresponding cells were used for gene expression studies.

\section{Determination of cell proliferation}

In order to obtain separate growth kinetics during the exponential growth phase for both, separately and cocultured cells, cells of nine wells per condition (ADSCs alone, SCCs alone (A431- or primary SCCs), and both cell types in co-culture) were harvested with trypsin/EDTA once every 24 hours from Day 1 to Day 5 . The cells were stained with trypan blue and the viable cells were counted with a Neubauer chamber. The generation time was calculated by the formula: $\mathrm{G}$ (hours) $=(\log 2 \times \mathrm{T}) /(\log \mathrm{Y}-\log \mathrm{X})$ with $\mathrm{T}=$ time in culture (hours), $\mathrm{Y}=$ number of cells at the end of $\mathrm{T}, \mathrm{X}=$ number of cells at the beginning of $\mathrm{T}$. The results were evaluated using Student's $t$-test.

\section{Analysis of cell migration}

In order to determine the migration capacity of ADSC and SCCs alone (A431- or primary SCCs) and in coculture, the QCM 24-Well Colorimetric Cell Migration Assay (Merck Millipore) was performed. For this purpose, cells of each cell type were seeded in expansion medium either on the bottom of the supplied 24-well plate $(4,000$ cells per well) or onto the membrane of the transwell insert (3,500 cells per insert). Cells were cultured separately for 24 hours before co-culture conditions (ADSCs on the well plate bottom, SCCs in the transwell inserts and vice versa) were established for a further 24 hours. Both cell types alone in the inserts served as controls. For evaluation of the assay, the medium was removed and the inserts transferred into new wells containing $400 \mu \mathrm{l}$ cell stain for 20 minutes. The inserts were washed with water and the non-migrated cells were removed from the interior of the inserts with cotton-tipped swabs. The dried inserts were transferred into $200 \mu \mathrm{l}$ of Extraction Buffer for 15 minutes and the optical density of $100 \mu \mathrm{l}$ extracted dye was measured at $560 \mathrm{~nm}$. The results were evaluated using Student's $t$-test.

\section{In vitro analysis of invasive behavior}

The invasion capacity of ADSC and SCCs was tested in a Cell Invasion Assay Kit (QCM ECMatrix Cell Invasion Assay, Merck Millipore). Cells of each cell type were 
seeded in expansion medium either on the bottom of the supplied 24-well plate (4,000 cells per well) or onto the membrane of the transwell insert (3,500 cells per insert). Cells were cultured separately for 24 hours (ADSCs) or 72 hours (SCCs) before co-culture - ADSCs on the bottom and SCCs in the inserts and vice versa was induced for a further 72 hours. Both cell types alone in the inserts served as controls. Next, the medium was removed, the non-invading cells of the interior of the inserts were cleared with cotton-tipped swabs and the inserts transferred into $500 \mu \mathrm{l}$ of staining solution for 20 minutes. Inserts were washed with water, airdried and transferred into $200 \mu \mathrm{l}$ of extraction buffer. The optical density of $150 \mu \mathrm{l}$ extracted dye was measured at $560 \mathrm{~nm}$. The results were evaluated using Student's $t$-test.

\section{Quantitative real-time polymerase chain reaction (qrt-PCR)}

The analysis of gene expression was carried out for 229 different genes in four main tumor associated areas: chemokines, apoptosis, molecular mechanisms of cancer and metastasis. Total RNA was isolated from ADSCs and SCCs, either cultured alone or in co-culture for four days, using the Trizol plus Kit (Life Technologies, Carlsbad, CA, USA). The RNA-concentration was calculated by Quant-iT RNA-Assay (Life Technologies) and $1 \mu \mathrm{g}$ was subjected to cDNA synthesis by the High Capacity cDNA Reverse Transcription Kit (Life Technologies). Gene expression analysis was performed on a Step One Plus Instrument (Life Technologies) using TaqMan Real Time PCR technology. Gene expression was analyzed by using pre-designed TaqMan 96-well array plates each containing 92 different genes of interest and 4 endogenous controls with 10 ng cDNA per well (Human Molecular Mechanisms of cancer \#4418806, Human Chemokines \#4366072, Human Cellular Apoptosis Pathway \#4418762, Human Tumor Metastasis \#4418743, Life Technologies). In order to further investigate a potential epithelial to mesenchymal transition (EMT) of the cells during co-culture the gene expression of E- and N-cadherin was analyzed using specific TaqMan gene expression assays (Hs01023894 for E-cadherin, Hs00983056 for N-cadherin) with $10 \mathrm{ng}$ of cDNA per sample. Calculating the difference between the cycle threshold (CT) of the genes of interest and the CT of the endogenous controls from the same sample provided delta-CT values.

\section{Human cytokine magnetic 30-plex panel}

In order to quantify the level of 30 cytokines (CCL2, CCL3, CCL4, CCL5, CXCL-9, CXCL-10, EGF, Eotaxin, FGF-2, G-CSF, GM-CSF, HGF, IFN- $\alpha$, IL- $1 \beta$, IFN- $\gamma$, IL1ra, IL-2, IL-2r, IL-4, IL-5, IL-6, IL-7, IL-8, IL-10, IL-12, IL-13, IL-15, IL-17, TNF- $\alpha$ and VEGF) and 8 different matrix metalloproteinases (MMP 1, 3, 7, 8, 9, 10, 12, 13) simultaneously in samples of ADSCs monoculture, SCCs monoculture, and ADSC-SCC-co-culture, a human cytokine magnetic 30-plex (LHC6003M and LHC6002, Life Technologies) and a human MMP magnetic Luminex Performance Assay were conducted according to the manufacturer's instructions. Samples were analyzed with a Luminex 200 instrument (BioRad). The median fluorescent intensity was determined and the cytokine/MMP concentration ascertained based on the standard curves for each cytokine/MMP.

\section{Analysis of angiogenic properties}

In order to determine the pro-angiogenic effect of ADSCs and A-431-SCCs or the primary SCCS alone or in co-culture, supernatants of each condition were collected at Day 4 of cell culture and analyzed for induction of tube formation in human umbilical vein endothelial cells (HUVEC) in an in vitro angiogenesis assay kit (Merck Millipore \# ECM 625) according to the manufacturer's instructions. In brief, wells of a 96-well plate were coated with an ECM Matrix solution, and 7,500 HUVEC cells were seeded onto the matrix in each well. The different conditioned media from ADSCs, A431-SCCs, pSCCs, or ADSC-SCC-co-cultures were added and incubated for 18 hours. Tube formation was visualized with a light microscope. A positive control was induced by Phorbol 12-myristate 13-acetate (PMA) (Abcam, Cambridge, UK; no. ab120297).

\section{Results}

\section{Determination of stemness}

The stemness of the applied ADSCs was determined according to the minimal consensus criteria for mesenchymal stem cells $[12,13]$ by analysis of distinct surface markers in flow cytometry and analysis of adipogenic and osteogenic differentiation with Oil Red and alizarin red staining, respectively.

\section{Flow cytometry}

ADSCs were positive for CD13, CD29, CD44, CD49a, CD63, CD73, CD90, CD105 and CD166. ADSCs were negative for CD31, CD34, CD45 and CD106 (Figure 1).

\section{Differentiation}

Adipogenic and osteogenic differentiations were induced to evaluate the multipotent differentiation potential. In all donors adipogenically induced cells showed a significantly higher oil red staining than non-induced control cells (Figure 2a). Osteogenically differentiated ADSC showed significantly higher extracellular calcium deposition than non-induced control cells, analyzed with alizarin red stain (Figure 2b). The cells, therefore, meet 


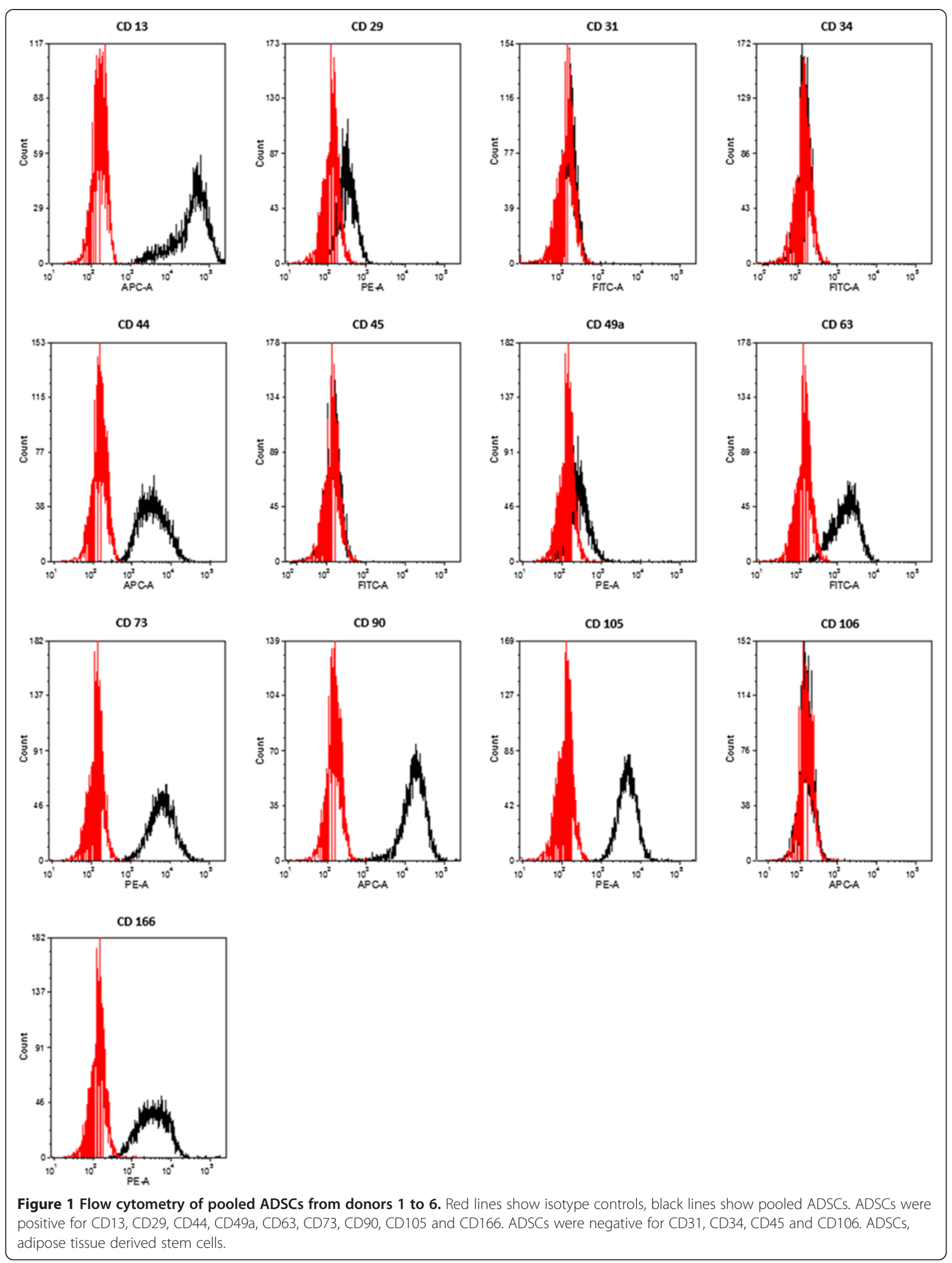




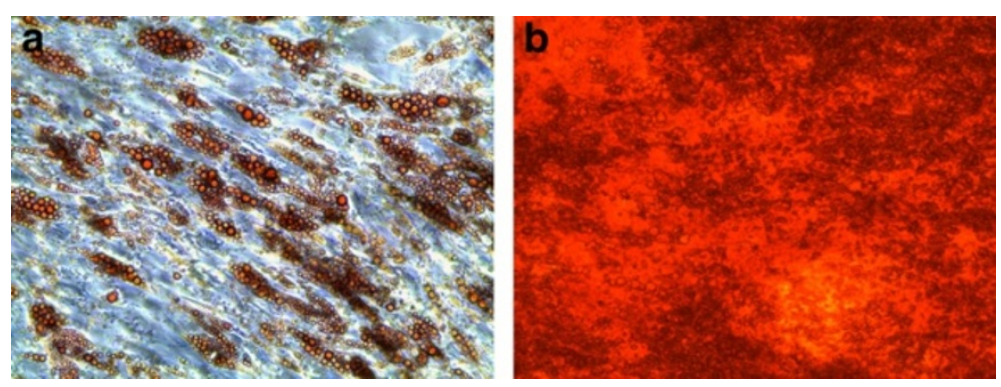

Figure 2 Representative light microscopical pictures of adipogenically and osteogenically differentiated ADSCs. Magnification 10x. (a) Intracellular lipid droplets stained by oil red method as a marker of adipogenic differentiation on Day 14 of differentiation. (b) Extracellular calcium deposition stained with alizarin red as a marker for osteogenic differentiation on Day 42 of differentiation. Undifferentiated controls are not shown. ADSCs, adipose tissue derived stem cells.

the minimal consensus criteria for mesenchymal stem cells $[12,13]$.

\section{Proliferation}

Cell proliferation was determined by analyzing the cells' doubling time during the exponential growth phase (in general from days 2 to 4 ) (Figure 3). Data are given as means with standard deviation (SD). Changes in cell numbers per time are given in Figure 3.

\section{ADSCs-A431-SCCs-co-culture}

When ADSCs were cultured alone on a regular culture surface in the six-well plate, the mean doubling time was 20 hours (SD 11), when cultured alone in a transwell insert, the mean cell doubling time was 17 hours (SD 5). A431-SCCs cultured alone in a six-well plate showed a doubling of cell number after a mean of 17 hours (SD 7 ), in a transwell insert after 16 hours (SD 4). When cocultured in a transwell system, the growth of ADSCs on the six-well plate significantly increased to a mean doubling time of 14 hours (SD 3, $P=0.038$ ) (Figure 3a). In the transwell insert the growth rate of co-cultured ADSCs slowed down to a mean doubling time of 19 hours (SD 9), that of A431-SCCs slowed down to a mean doubling time of 25 hours (SD 13) in the six-well plate, and to 21 hours (SD 8 ) in the transwell insert (Figure $3 \mathrm{~b}$ ). These changes, however, were not statistically significant $(P>0.05)$.

\section{ADSCs-pSCCs-co-culture}

When ADSCs were cultured alone on a regular culture surface in the six-well plate the mean doubling time was 26 hours (SD 8), when cultured alone in a transwell insert, the mean cell doubling time was 28 hours (SD 7). Primary SCCs cultured alone in a six-well plate showed a doubling of cell number after a mean of 18 hours (SD 3 ), in a transwell insert after 21 hours (SD 6).

Co-culturing ADSCs with primary SCCs resulted in a decreased proliferation determined by a significantly longer doubling time in ADSCs cultured on the six-well plate (42 hours, SD 13, $P=0.03$ ) or in the transwell system (51 hours, SD 25) (Figure 3c). In co-culture, primary SCCs also significantly decreased their proliferation (25 hours, SD 4, $P<0.001$ ), if cultured on the plate (Figure 3d). If ADSCs were cultured in the transwell insert, there was no significant change in proliferative activity (22 hours (SD 4 ), $P>0.05$ ).

\section{Quantitative real time-PCR}

Co-cultured ADSCs and SCCs (A431-SCCs and primary $\mathrm{SCCs}$ ) showed strong differences in the gene expression levels compared to a mono-culture of ADSCs or SCCs. Results were greatly similar for the two analyzed coculture systems (ADSCs on plate/SCCs in transwell insert, and ADSCs in transwell insert/SCCs on plate). To facilitate clear data presentation, only results of the ADSCs on plate/SCCs in transwell insert - co-culture, and (except for E- and N-Cadherin) changes in gene expression 2.5-fold or greater are displayed.

\section{Co-culture of A431-SCCs and ADSCs}

In the ADSCs, a strong increase of the gene expression level could be found in CSF-3 (258-fold), CXCL6 (129fold), IL-1 $\beta$ (119-fold), MMP-3 (108-fold), IL-6 (88-fold), PTGS2 (74-fold), CXCL1 (54-fold), CCL8 (42-fold), CSF-2 (38-fold), CCL20 (32-fold), IL-8 (29-fold), CXCL3 (27-fold), CXCL2 (16-fold), CXCL12 and IL-1 $\alpha$ (12-fold), CCL7 (11-fold), CCL2 and CXCL5 (9.4-fold), CCL13 (8fold), LYPD3 and WISP-1 (6.1-fold) and FGFR4 (5.4-fold).

To a lesser extent the expression of NR4A3 (4.7-fold), TLR-2 (4.6-fold), CXCL11, MCAM, STAT4 and NFKBIA (4.0-fold), MMP-2 and TYMP (3.4-fold), PIK3CD and PPBP (3.3-fold), NFKB2 and RELB (2.7-fold), FGF2 (2.5fold), GPR81 (2.4 fold), TNF and CCRL1 (2.3-fold) was also up-regulated (see Table 1, part 1 and Additional file 1: Table S1, A, part 1). 

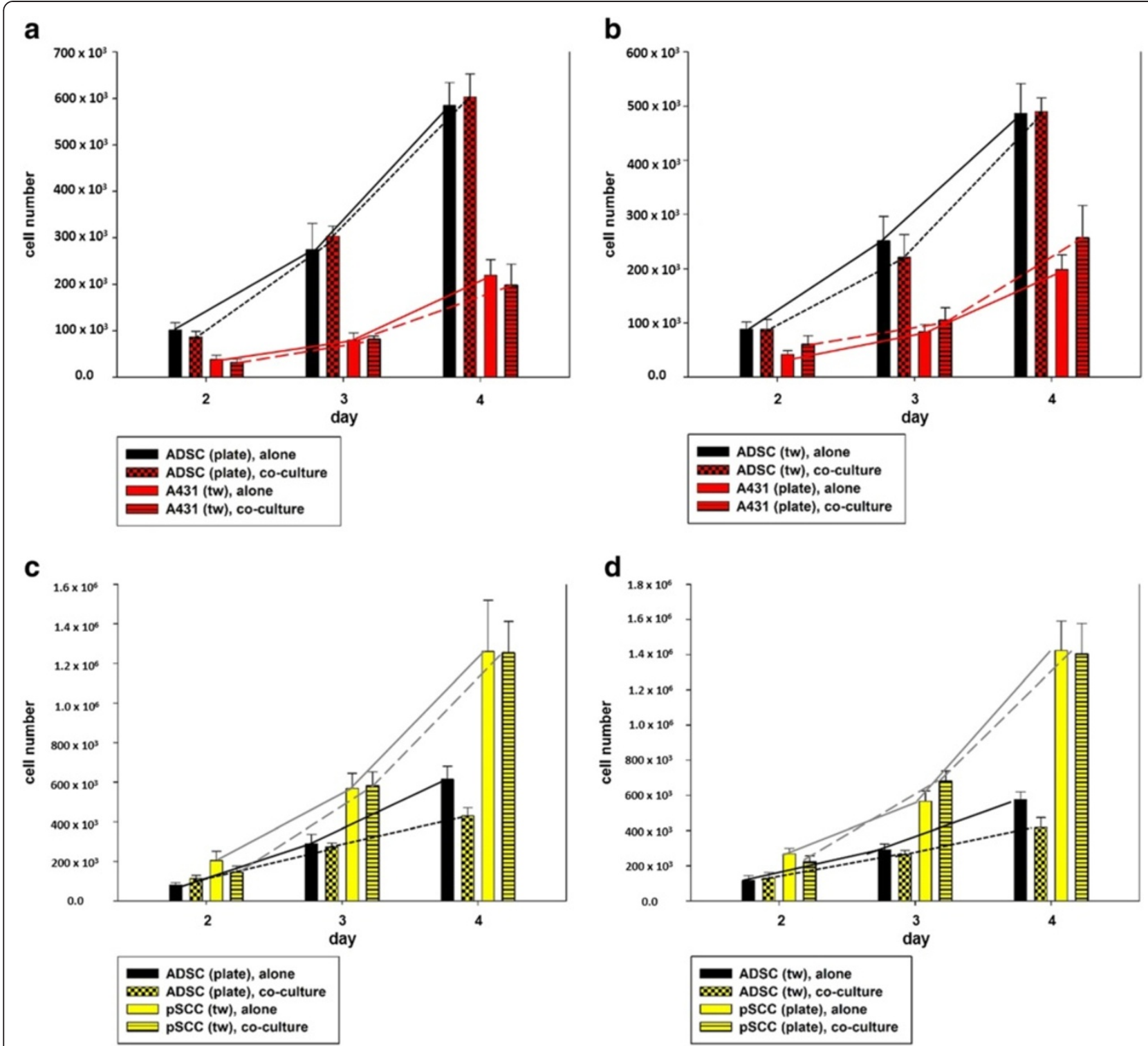

Figure 3 Effect of ADSC-SCC-co-culture on cells' proliferative activity. (a) The growth of ADSCS on the plate significantly increased $(P=0.038)$ in co-culture with A431-SCCs in the transwell insert compared to mono-culture. The growth of co-cultured A431-SCCs in the transwell insert was not significantly affected $(P>0.05)$. (b) ADSC-SCC-Co-culture with A431-SCCs on the six-well plate and ADSCs in the transwell insert did not significantly affect cell growth of both cell types $(P>0.05)$. (c) ADSC-SCC-Co-culture with ADSCs on the six-well plate and pSCCs in the transwell insert significantly reduced ADSCs' growth compared to mono-culture $(P=0.03)$. The proliferative activity of pSCCs in co-culture was not affected $(P>0.05)$. (d) ADSC-SCC-co-culture with pSCCs on the six-well plate and ADSCs in the transwell insert significantly decreased the growth of pSCCs $(P<0.001)$, that of co-cultured ADSCs was not significantly affected $(P>0.05)$. ADSC, adipose tissue derived stem cells; SCCs, squamous cell carcinoma cells.

When A431-SCCs were co-cultured with ADSCs the following genes were strongly up-regulated in the A431SCCs: MMP-3 (191-fold), N-Cadherin (97-fold), HGF (20-fold), TWIST1 (11-fold), ITGB3 (10-fold), MMP-1 (9.4-fold), and others to a lesser extent: $M M P-7$ (4.8-fold), CTSK (4.1-fold), MMP-2 (3.1-fold), CYCS (3-fold), PTGS2 (2.7-fold), PPBP, IKBKE and ETV4 (2.5-fold), CCL2O and FN1 (2.4-fold) and MCAM (2.3-fold). In addition,
$\mathrm{N}$-Cadherin-expression in A431-SCCs is strongly upregulated in co-culture (71-fold) while there is no significant change in co-cultured ADSCs (1.1-fold).

ADSCs did not express E-Cadherin in mono-culture; in co-culture however, E-Cadherin expression was strongly up-regulated. In co-cultured A431-SCCs, E-Cadherin was slightly down-regulated (1.2-fold). Furthermore, the expression of CXCL9 (4.4-fold), CXCL10 (4.8.-fold), FOS 
Table 1 Changes in the gene expression levels of ADSCs and A431-SCCs in co-culture compared to mono-culture

\begin{tabular}{llll}
\hline Gene & $\begin{array}{l}\text { Fold ADSC } \\
\text { mono-/co-culture }\end{array}$ & $\begin{array}{l}\text { Up-/down- } \\
\text { regulation }\end{array}$ & $\begin{array}{l}\text { Main impact } \\
\text { of gene product }\end{array}$ \\
\hline
\end{tabular}

Part 1. Changes in the gene expression of ADSCS

\begin{tabular}{|c|c|c|c|}
\hline E-Cadherin & n.d. & $\rightarrow$ & EMT, i, m, ms \\
\hline $\mathrm{N}$-Cadherin & $1.0(0.0)$ & $\rightarrow$ & EMT \\
\hline CCL2 & $9.4(5.0)$ & $\uparrow$ & $a, i, m, m s, p, E M T$ \\
\hline CCL7 & $11(3.8)$ & $\uparrow$ & $a, i, m, m s, p$ \\
\hline CCL8 & $42(15)$ & $\uparrow$ & $a, i, m, p$ \\
\hline CCL13 & $8.0(0.0)$ & $\uparrow$ & $a, i, m, p$ \\
\hline CCL2O & $32(23)$ & $\uparrow$ & $\mathrm{im}$ \\
\hline CSF-2 & $38(20)$ & $\uparrow$ & $a, i, m$ \\
\hline CSF-3 & $258(2.3)$ & $\uparrow$ & $\mathrm{im}$ \\
\hline CXCL1 & $54(16)$ & $\uparrow$ & $a, i, m, m s, p$ \\
\hline CXCL2 & $16(0.0)$ & $\uparrow$ & $a, i, m$ \\
\hline CXCL3 & $27(7.8)$ & $\uparrow$ & $\mathrm{a}, \mathrm{i}, \mathrm{m}$ \\
\hline CXCL5 & $9.4(5.0)$ & $\uparrow$ & $a, i, m$ \\
\hline CXCL6 & $129(0.2)$ & $\uparrow$ & $a, i, m, m s, p$ \\
\hline CXCL11 & $4.0(0.0)$ & $\uparrow$ & $a, i, m$ \\
\hline CXCL12 & $12(5.7)$ & $\uparrow$ & $a, i, m$ \\
\hline$I L-1 a$ & $12(5,6)$ & $\uparrow$ & $\mathrm{a}, \mathrm{ms}$ \\
\hline $\mathbb{I L}-1 \beta$ & $119(100)$ & $\uparrow$ & $\mathrm{a}, \mathrm{ms}$ \\
\hline IL-6 & $88(84)$ & $\uparrow$ & $p$ \\
\hline $\mathbb{I L}-8$ & $29(25)$ & $\uparrow$ & a \\
\hline LYPD3 & $6.1(2.9)$ & $\uparrow$ & $\mathrm{i}, \mathrm{ms}$ \\
\hline$M M P-3$ & $108(32)$ & $\uparrow$ & $m, i, m s$ \\
\hline$N R 4 A 3$ & $4.7(2.8)$ & $\uparrow$ & $p$ \\
\hline PTGS2 & $74(39)$ & $\uparrow$ & $a, i, i m, m, m s, p$ \\
\hline$T L R-2$ & $4.6(2.5)$ & $\uparrow$ & $a, m, i$ \\
\hline WISP-1 & $6.1(2.9)$ & $\uparrow$ & $\mathrm{m}, \mathrm{im}$ \\
\hline Gene & $\begin{array}{l}\text { Fold A431-SCC } \\
\text { mono-/co-culture }\end{array}$ & $\begin{array}{l}\text { Up-/down- } \\
\text { regulation }\end{array}$ & $\begin{array}{l}\text { Main impact of } \\
\text { gene or gene } \\
\text { product }\end{array}$ \\
\hline
\end{tabular}

Part 2. Changes in the gene expression of A431-SCCS

$\begin{array}{llll}\text { E-Cadherin } & * & \downarrow \downarrow & \text { EMT, i, m, ms } \\ \text { N-Cadherin } & 98(2.3) & \uparrow & \text { EMT } \\ \text { CXCL9 } & 4.4(0.2) & \downarrow & \mathrm{a} \\ \text { CXCL10 } & 4.8(0.1) & \downarrow & \mathrm{a} \\ \text { CTKS } & 4.1(2.9) & \uparrow & \mathrm{m}, \mathrm{i}, \mathrm{ms} \\ \text { FN1 } & 2.5(1.3) & \uparrow & \mathrm{m}, \mathrm{i} \\ \text { HGF } & 20(12) & \uparrow & \mathrm{a}, \mathrm{m}, \mathrm{i}, \\ \text { ITGB3 } & 10(5.1) & \uparrow & \mathrm{m}, \mathrm{i}, \mathrm{ms} \\ \text { MMP-1 } & 9.4(5.1) & \uparrow & \mathrm{m}, \mathrm{i}, \mathrm{ms} \\ \text { MMP-2 } & 3.1(1.5) & \uparrow & \mathrm{m}, \mathrm{i}, \mathrm{ms} \\ \text { MMP-3 } & 191(89) & \uparrow & \mathrm{m}, \mathrm{i}, \mathrm{ms} \\ \text { MMP-7 } & 4.8(2.4) & \uparrow & \mathrm{m}, \mathrm{i}, \mathrm{ms}\end{array}$

Table 1 Changes in the gene expression levels of ADSCs and A431-SCCs in co-culture compared to mono-culture (Continued)

\begin{tabular}{llll}
\hline MMP-9 & $3.4(0.2)$ & $\downarrow$ & $\mathrm{m}, \mathrm{i}, \mathrm{ms}$ \\
PTGS2 & $2.7(0.8)$ & $\uparrow$ & $\mathrm{a}, \mathrm{i}, \mathrm{im}, \mathrm{m}, \mathrm{ms}, \mathrm{p}$ \\
TWIST-1 & $11(3.8)$ & $\uparrow$ & $\mathrm{ms}$ \\
\hline
\end{tabular}

*In co-culture with ADSCs E-Cadherin expression is down-regulated in primary SCC to undetectable levels.

GUSB was used as referring housekeeping-gene. Except for $E$ - and $\mathrm{N}$-Cadherin only changes of 2.5 -fold or higher are displayed. Part 1 displays the changes in the gene expression levels of ADSCs. Part 2 shows the changes in the gene expression levels of A431-SCCs. Arrows mark an up- $(\uparrow)$ or down-regulation $(\downarrow)$ of the gene expression compared to the referring mono-culture. Abbreviations of main impact: a, angiogenesis; i, invasion, im, impaired anti-tumor response; $\mathrm{m}$, migration; ms, metastasis; $p$, proliferation.;Furthermore a mild down-regulation of E2F1 (3.2-fold), CCND1, CCND3, CYCS and DVL1 (2.7-fold) and SPP1 (2.6-fold) could be determined.

(4-fold), MMP-9 (3.4-fold) and PMAIP1 (3.1-fold) was also down-regulated (see Table 1, part 2 and Additional file 1: Table S1, A, part 2).

\section{Co-culture of primary SCCs and ADSCs}

In the ADSCs a strong increase of the gene expression level could be found in IL-6 (65-fold), CXCL6 (64-fold), CSF-3 (63-fold), IL-8 and CCL20 (32-fold), CCL28 (27fold), PTGS2 (22-fold), TLR-2 (21-fold), WISP-1 (20-fold), CCL5, CXCL1, CXCL3 and IL-1 3 (16-fold), MMP-3, IL$1 \alpha$ and CSF-2 (13-fold), CXCL5 (8.1-fold), VEGFA (6.7), KISS1R (5.6-fold), CXCL14, ITGA2B and SERPINE (5.4fold). To a lesser extent the expression of CCL2 and CXCL2 (4-fold), CCL7, CCL8 and PIK3CD (3.4-fold), CXCR4 (3.1-fold), CXCL11, CXCL12, CCL3, CCL13, FGFR4, MMP-2, MMP-9 and TPBG (2.7-fold) was also up-regulated (see Table 2, part 1 and Additional file 1: Table S1, B, part 1). ADSCs did not express E-Cadherin in mono-culture, and it could not be determined in cocultured ADSCs either. There was no significant change of N-Cadherin-expression in ADSCs in co-culture (1.1fold). A mild down-regulation of FOS and BCL2 (3-fold) could be determined.

When primary SCCs were co-cultured with ADSCs the CCND2 gene was up-regulated (4.7-fold) and the following genes were down-regulated: TNF (2.7-fold) and CCL5 (3.0-fold) (see Table 2, part 2 and Additional file 1: Table S1, B, part 2). E-Cadherin-expression and $\mathrm{N}$-Cadherin gene expression was not significantly changed during co-culture with ADSCs (1.5-fold, and 3.0-fold).

\section{Multiplex protein analysis}

Co-culture of A431-SCCS and ADSCs

When ADSC were co-cultured with A431-SCCs cells (see Table 3), a very strong increase in the protein concentration in the conditioned medium could be detected for G-CSF (357-fold), INF- $\alpha$ (118-fold), GM-CSF (106-fold), MMP-9 (45-fold), IL-6 (43-fold), MMP-3 (6.8-fold), and 
Table 2 Changes in the gene expression levels of ADSCs and pSCCs in co-culture compared to mono-culture

\begin{tabular}{|c|c|c|c|}
\hline Gene & Fold ADSC mono-/co-culture & Up-/down-regulation & Main impact of gene or gene product \\
\hline \multicolumn{4}{|c|}{ Part 1. Changes in the gene expression of ADSCS } \\
\hline E-Cadherin & n.d. & n.a. & EMT, i, m, ms \\
\hline $\mathrm{N}$-Cadherin & $0.9(0.0)$ & $\rightarrow$ & EMT \\
\hline$C C L 5$ & $16(0.1)$ & $\uparrow$ & $a, i, m s, p$ \\
\hline CCL2O & $32(0.4)$ & $\uparrow$ & $\mathrm{im}$ \\
\hline CCL28 & $27(7.6)$ & $\uparrow$ & $a, i, m s, p$ \\
\hline CSF-2 & $13(4,3)$ & $\uparrow$ & $\mathrm{a}, \mathrm{i}, \mathrm{m}$ \\
\hline CSF-3 & $63(0.2)$ & $\uparrow$ & $\mathrm{im}$ \\
\hline CXCL1 & $16(0.0)$ & $\uparrow$ & $a, i, m, m s, p$ \\
\hline CXCL2 & $4.0(0.0)$ & $\uparrow$ & $\mathrm{a}, \mathrm{i}, \mathrm{m}$ \\
\hline CXCL3 & $16(0.1)$ & $\uparrow$ & $a, i, m$ \\
\hline CXCL5 & $8.1(0.0)$ & $\uparrow$ & $a, i, m$ \\
\hline CXCL6 & $64(0.2)$ & $\uparrow$ & $a, i, m, m s, p$ \\
\hline CXCL14 & $5.4(1.9)$ & $\uparrow$ & $a$ \\
\hline $\mathbb{L L}-1 a$ & $13(3.7)$ & $\uparrow$ & $\mathrm{a}, \mathrm{ms}$ \\
\hline $\mathbb{L L}-1 \beta$ & $16(0.1)$ & $\uparrow$ & $\mathrm{a}, \mathrm{ms}$ \\
\hline $\mathbb{I L}-6$ & $65(0.8)$ & $\uparrow$ & $\mathrm{p}$ \\
\hline $\mathbb{I L}-8$ & $32(0.7)$ & $\uparrow$ & a \\
\hline ITGA2B & $5.4(1.9)$ & $\uparrow$ & $m, i, m s$ \\
\hline KISSIR & $5.6(2.0)$ & $\uparrow$ & ms \\
\hline$M M P-3$ & $13(3.8)$ & $\uparrow$ & $m, i, m s$ \\
\hline PTGS2 & $22(7.8)$ & $\uparrow$ & $a, i, i m, m, m s, p$ \\
\hline SERPINE1 & $5.4(2.0)$ & $\uparrow$ & $\mathrm{i}, \mathrm{a}, \mathrm{m}$ \\
\hline$T L R-2$ & $21(7.6)$ & $\uparrow$ & $\mathrm{a}, \mathrm{ms}$ \\
\hline VEGFA & 6.7 (1.9) & $\uparrow$ & $a$ \\
\hline WISP-1 & $20(12)$ & $\uparrow$ & m, im \\
\hline Gene & Fold primary SCC mono-/co-culture & Up-/down-regulation & Main impact of gene or gene product \\
\hline \multicolumn{4}{|c|}{ Part 2. Changes in the gene expression of primary SCCS } \\
\hline E-Cadherin & $1.5(0.1)$ & $\rightarrow$ & EMT, i, m, ms \\
\hline $\mathrm{N}$-Cadherin & $3.0(0.0)$ & $\downarrow$ & EMT \\
\hline CCND2 & $4.7(3.9)$ & $\uparrow$ & i \\
\hline
\end{tabular}

GUSB was used as the referring housekeeping-gene. Except for E- and N-Cadherin only changes of 2.5-fold or higher are displayed. Part 1 displays the changes in the gene expression levels of ADSCs. Part 2 shows the changes in the gene expression levels of pSCCs. Arrows mark an up- $(\uparrow)$ or down-regulation ( $\downarrow)$ of the gene expression compared to the referring mono-culture. Abbreviations of main impact: a, angiogenesis; $\mathrm{i}$, invasion; im, impaired anti-tumor response; $\mathrm{m}$, migration; $\mathrm{ms}$, metastasis; $\mathrm{p}$, proliferation.

CCL2 (8-fold). VEGF (6.0-fold), MMP-10 (3.4-fold), INF- $\gamma$ (3.9-fold), CCL4 (3.5-fold), IL-7 (4.9-fold), IL-8 (5.4-fold), IL-13 (3.5-fold) and IL-12 (2.8-fold) were only moderately increased. The concentrations of bFGF, CCL3, CXCL10, Eotaxin, HGF, IL-4, IL-10, IL-15, IL-17, MMP-1 and TNF- $\alpha$ were not significantly changed compared to the mono-culture of ADSCs ( $<2.5$-fold change).

Exclusively in co-culture ADSCs were exposed to CXCL9 (441 pg/ml, SD 24), IL-1 $\beta$ (11 pg/ml, SD 4.9), IL-1Ra (687 pg/ml (SD 65)), IL-2R (50 pg/ml, SD 31) and MMP-7 (131 pg/ml, SD 42).
With regard to A431-SCCs mono-culture, the coculture with ADSCs led to a very strong increase in MMP-3 (1527-fold), MMP-1 (143-fold), IL-6 (301-fold), CCL2 (126-fold), HGF (118-fold), G-CSF (29-fold), MMP-10 (17-fold), MMP-9 (13-fold), and IL-8 (13-fold), and a moderate increase of CCL4 (7.4-fold), INF- $\alpha$ (6.7fold), IL-7 (3.0-fold) and VEGF (2.8-fold). Compared to a A431-SCC-mono-culture, co-culturing with ADSCs did not significantly change the concentration of bFGF, CCL3, CXCL10, Eotaxin, GM-CSF, IL-1 $\beta$, IL-4, IL-10, IL-12, IL-13, IL-15, IL-17, IL-1Ra, IL-2R and TNF- $\alpha$. In 
Table 3 Changes in the protein expression levels of ADSCs and A431-SCCs in co-culture compared to mono-culture

\begin{tabular}{|c|c|c|c|c|c|}
\hline Protein & $\begin{array}{l}\mathrm{Pg} / \mathrm{ml}, \text { ADSC } \\
\text { mono-culture }\end{array}$ & $\begin{array}{l}\mathrm{Pg} / \mathrm{ml}, \mathrm{A} 431 \\
\text { mono-culture }\end{array}$ & $\mathrm{Pg} / \mathrm{ml}$, co-culture & $\begin{array}{l}\text { Fold ADSC } \\
\text { mono-/co-culture }\end{array}$ & $\begin{array}{l}\text { Fold A431 } \\
\text { mono-/co-culture }\end{array}$ \\
\hline bFGF & $4.7(1.8)$ & $7.8(1.6)$ & $7.5(2.0)$ & $1.6-\rightarrow$ & $1.0-\rightarrow$ \\
\hline CCL2 & $2,498(821)$ & $168(23)$ & $21,096(4,041)$ & $8.5-\uparrow$ & $126-\uparrow$ \\
\hline CCL3 & $24.1(1.4)$ & $22.4(1.9)$ & $39.2(2.9)$ & $1.6-\rightarrow$ & $1.7-\rightarrow$ \\
\hline CCL4 & $5.8(3.6)$ & $2.7(2.5)$ & $20(2.7)$ & $3.5-\uparrow$ & $7.4-\uparrow$ \\
\hline CCL5 & n.d. & $13(2.5)$ & n.d. & $--\rightarrow$ & $--\downarrow$ \\
\hline CXCL9 & n.d. & n.d. & $411(24)$ & $--\uparrow$ & $--\uparrow$ \\
\hline CXCL10 & $4.9(0.3)$ & $4.6(0.1)$ & $6.4(0.3)$ & $1.3-\rightarrow$ & $1.2-\rightarrow$ \\
\hline Eotaxin & $1.7(0.1)$ & $1.6(0.3)$ & $1.8(0.6)$ & $1.1-\rightarrow$ & $1.2-\rightarrow$ \\
\hline G-CSF & $98(19)$ & $1,225(135)$ & $34,941(4,830)$ & $357-\uparrow$ & $29-\uparrow$ \\
\hline GM-CSF & $1.3(0.2)$ & $100(8.9)$ & $133(28)$ & $106-\uparrow$ & $1.3-\rightarrow$ \\
\hline HGF & $6,892(1,788)$ & $34(15)$ & $4,049(746)$ & $0.6-\rightarrow$ & $118-\uparrow$ \\
\hline IL-1b & n.d. & $6.1(3.2)$ & $11(4.9)$ & $--\uparrow$ & $1.8-\rightarrow$ \\
\hline$\| \mathrm{L}-2$ & $5.6(1.4)$ & $5.9(0.8)$ & $6.2(0.9)$ & $--\rightarrow$ & $--\rightarrow$ \\
\hline $\mid \mathrm{L}-4$ & $22(1.3)$ & $19(0.7)$ & $31(1.8)$ & $1.4-\rightarrow$ & $1.6-\rightarrow$ \\
\hline IL-6 & $313(80)$ & $45(4.1)$ & $13,563(917)$ & $43-\uparrow$ & $301-\uparrow$ \\
\hline IL-7 & $20(7.5)$ & $33(8.3)$ & $100(19)$ & $4.9-\uparrow$ & $3.0-\uparrow$ \\
\hline IL-8 & $9,213(3,483)$ & 3,898 (404) & $49,441(1,572)$ & $5.4-\uparrow$ & $13-\uparrow$ \\
\hline $\mid \mathrm{L}-10$ & $7.3(0.3)$ & $7.8(0.3)$ & $16(0.6)$ & $2.2-\rightarrow$ & $2.0-\rightarrow$ \\
\hline $\mid \mathrm{L}-12$ & $27.4(8.0)$ & $35.2(7.8)$ & $76(5.1)$ & $2.8-\uparrow$ & $2.2-\rightarrow$ \\
\hline IL-13 & $18(1.0)$ & $20(1.3)$ & $27(1.1)$ & $3.5-\uparrow$ & $1.4-\rightarrow$ \\
\hline IL-15 & $36(11)$ & $38(19)$ & $33(20)$ & $0.9-\rightarrow$ & $0.9-\rightarrow$ \\
\hline $\mid \mathrm{L}-17$ & $11.2(0.7)$ & $9.6(0.7)$ & $14(1.2)$ & $1.3-\rightarrow$ & $1.5-\rightarrow$ \\
\hline IL-1Ra & n.d. & $1,084(82)$ & $687(65)$ & $0.6-\rightarrow$ & $0.6-\rightarrow$ \\
\hline$I L-2 R$ & n.d. & $109(0.0)$ & $50(31)$ & $--\uparrow$ & $0.5-\rightarrow$ \\
\hline INF-a & $84(16)$ & $40(5.4)$ & $268(14)$ & $118-\uparrow$ & $6.7-\uparrow$ \\
\hline INF- $\gamma$ & $2.3(0.9)$ & $5.7(1.4)$ & $8.8(2.4)$ & $3.9-\uparrow$ & $1.5-\rightarrow$ \\
\hline MMP-1 & $33,056(5,448)$ & $302(33)$ & $43,274(15,154)$ & $1.3-\rightarrow$ & $143-\uparrow$ \\
\hline MMP-3 & $16,089(3,424)$ & $72(7)$ & $109,950(47,520)$ & $6.8-\uparrow$ & $1,527-\uparrow$ \\
\hline MMP-7 & n.d. & n.d. & $131(42)$ & $--\uparrow$ & $--\uparrow$ \\
\hline MMP-9 & $156(18)$ & $533(57)$ & $6,987(15,036)$ & $45-\uparrow$ & $13-\uparrow$ \\
\hline MMP-10 & $357(67)$ & $70(2.3)$ & $1,202(333)$ & $3.4-\uparrow$ & $17-\uparrow$ \\
\hline TNF-a & $2.7(1.3)$ & $2.5(1.0)$ & $4.1(2.0)$ & $1.5-\rightarrow$ & $1.7-\rightarrow$ \\
\hline VEGF & $61(11)$ & $132(22)$ & $362(40)$ & $6.0-\uparrow$ & $2.8-\uparrow$ \\
\hline
\end{tabular}

CXCL9 and MMP-7 could only be detected in co-culture. Standard deviation is given in brackets. Results from 0 to 9.9 are shown with one decimal, results 10 or higher are displayed without decimals. n.d., not detectable; - -, not applicable.

contrast to that, CCL5 was down-regulated to a no longer detectable level in co-cultured A431-SCCs.

CXCL-9 (411 pg/ml, SD 24) and MMP-7 (131 pg/ml, SD 42) were exclusively produced in co-culture but neither in the mono-culture of A431-SCCs nor of ADSCs.

\section{Co-culture of primary SCCs and ADSCs}

When ADSCs were co-cultured with primary SCCs cells (see Table 4), a strong increase in the protein concentration in the conditioned medium could be detected for G-CSF (77-fold) and GM-CSF (10-fold), and a moderate increase for IL-6 (5.5-fold), CCL4 (3.8-fold), IL-7 (3.4-fold), IL-8 (3.0-fold) and IL-2 (2.5-fold). Exclusively in co-culture, ADSCs were exposed to CCL5 and CXCL9.

For ADSCs, no major changes in the protein level of bFGF, CCL2, CCL3, CXCL10, Eotaxin, MMP-1, MMP-3, MMP-9, MMP-10, HGF, INF- $\alpha$, INF- $\gamma$, IL-4, IL-10, IL-12, IL-13, IL-17, TNF- $\alpha$ and VEGF $(<2.5$-fold 
Table 4 Changes in the protein expression levels of ADSCs and pSCCs in co-culture compared to mono-culture

\begin{tabular}{|c|c|c|c|c|c|}
\hline Protein & $\begin{array}{l}\mathrm{Pg} / \mathrm{ml}, \text { ADSC } \\
\text { mono-culture }\end{array}$ & $\begin{array}{l}\mathrm{Pg} / \mathrm{ml}, \mathrm{pSCC} \\
\text { mono-culture }\end{array}$ & $\mathrm{Pg} / \mathrm{ml}$, co-culture & $\begin{array}{l}\text { Fold ADSC } \\
\text { mono-/co-culture }\end{array}$ & $\begin{array}{l}\text { Fold pSCC } \\
\text { mono-/co-culture }\end{array}$ \\
\hline bFGF & $3.9(1.9)$ & $5.3(1.1)$ & $6.6(1.8)$ & $1.7-\rightarrow$ & $1.3-\uparrow$ \\
\hline CCL2 & $2,768(109)$ & $565(83)$ & 5,707 & $2.1-\rightarrow$ & $10-\uparrow$ \\
\hline CCL3 & $26(1.7)$ & $25(1.5)$ & $32(4.6)$ & $1.2-\rightarrow$ & $1.3-\rightarrow$ \\
\hline CCL4 & $2.9(2.0)$ & $2.0(0.0)$ & $11(4.9)$ & $3.8-\uparrow$ & $5.4-\uparrow$ \\
\hline CCL5 & n.d. & $216(32)$ & $95(8.4)$ & $--\uparrow$ & $0.4-\rightarrow$ \\
\hline CXCL9 & n.d. & n.d. & $208(14)$ & $--\uparrow$ & $--\uparrow$ \\
\hline CXCL10 & $4.7(0.2)$ & $5.7(0.5)$ & $7.0(0.8)$ & $1.5-\rightarrow$ & $1.2-\rightarrow$ \\
\hline Eotaxin & $1.7(0.4)$ & $1.8(0.3)$ & $2.1(0.2)$ & $1.3-\rightarrow$ & $1.2-\rightarrow$ \\
\hline GM-CSF & $1.0(0.1)$ & $13(0.9)$ & $32(4.6)$ & $10-\uparrow$ & $0.8-\rightarrow$ \\
\hline G-CSF & $40(23)$ & n.d. & $3,076(330)$ & $77-\uparrow$ & $--\uparrow$ \\
\hline $\mathrm{HGF}$ & $6,125(317)$ & $72(31)$ & $3,661(174)$ & $0.6-\rightarrow$ & $51-\uparrow$ \\
\hline IL-1b & n.d. & n.d. & $6.2(1.2)$ & $--\uparrow$ & $--\uparrow$ \\
\hline $\mathrm{IL}-2$ & $4.7(0.7)$ & $5.4(0.6)$ & $5.2(0.9)$ & $2.5-\uparrow$ & $1.0-\rightarrow$ \\
\hline $\mid \mathrm{L}-4$ & $22(0.9)$ & $21(0.6)$ & $29(2.1)$ & $1.3-\rightarrow$ & $1.4-\rightarrow$ \\
\hline IL-6 & $349(40)$ & $4.0(1.4)$ & $1,912(396)$ & $5.5-\uparrow$ & $480-\uparrow$ \\
\hline IL-7 & $16(1.2)$ & n.d. & $53(23)$ & $3.4-\uparrow$ & $--\uparrow$ \\
\hline IL-8 & $11,219(652)$ & $8,825(791)$ & $34,032(1,805)$ & $3.0-\uparrow$ & $3.9-\uparrow$ \\
\hline IL-10 & $7.3(0.0)$ & $6.4(0.6)$ & $9.5(0.7)$ & $1.3-\rightarrow$ & $1.5-\rightarrow$ \\
\hline $\mid \mathrm{LL}-12$ & $28(5.1)$ & $29(6.0)$ & $54(11)$ & $1.9-\rightarrow$ & $1.9-\rightarrow$ \\
\hline $\mid \mathrm{L}-13$ & $18(1.6)$ & $15(0.8)$ & $20(3.0)$ & $1.1-\rightarrow$ & $1.4-\rightarrow$ \\
\hline $\mid \mathrm{L}-17$ & $11(1.1)$ & $10(0.6)$ & $14(1.4)$ & $1.3-\rightarrow$ & $1.4-\rightarrow$ \\
\hline INF-a & $102(5.6)$ & $61(6.6)$ & $156(12)$ & $1.5-\rightarrow$ & $2.6-\uparrow$ \\
\hline INF- $\gamma$ & $2.2(0.5)$ & $3.0(1.4)$ & $6.1(3.5)$ & $1.6-\rightarrow$ & $1.0-\rightarrow$ \\
\hline MMP-1 & $44,830(2,372)$ & n.d. & $24,473(1,564)$ & $1.8-\rightarrow$ & $--\uparrow$ \\
\hline MMP-3 & $2,288(268)$ & $47(2.6)$ & $4,354(386)$ & $1.9-\rightarrow$ & $92-\uparrow$ \\
\hline MMP-9 & $110(5.2)$ & 275 (19) & $174(11)$ & $1.6-\rightarrow$ & $1.6-\rightarrow$ \\
\hline MMP-10 & $149(14)$ & $17(3.5)$ & $248(13)$ & $1.7-\rightarrow$ & $14-\uparrow$ \\
\hline TNF-a & $2.1(0.5)$ & $3.2(0.9)$ & $3.2(1.9)$ & $1.6-\rightarrow$ & $1.0-\rightarrow$ \\
\hline VEGF & $63(8.7)$ & $26(8.1)$ & $117(30)$ & $1.9-\rightarrow$ & $4.6-\uparrow$ \\
\hline
\end{tabular}

CXCL9 and IL-1 $\beta$ could only be detected in co-culture. Standard deviation is given in brackets. Results from 0 to 9.9 are shown with one decimal, results 10 or higher are displayed without decimals. n.d., not detectable, -- , not applicable.

change) could be detected in co-culture compared to mono-culture.

With regard to SCCs mono-culture, the co-culture with ADSCs led to a very strong increase in IL-6 (480-fold), MMP-3 (92-fold), HGF (51-fold), MMP10 (14-fold), CCL2 (10-fold), and a moderate increase in CCL4 (5.4-fold), VEGF (4.6-fold), IL-8 (3.9-fold) and INF- $\alpha$ (2.6).

Compared to a pSCC-mono-culture, co-culturing with ADSCs did not significantly change the concentration of bFGF, CCL3, CCL5, CXCL10, Eotaxin, GM-CSF, IL-2, IL-4, IL-10, IL-12, IL-13, IL-17, IL-1Ra, IL-2R, INF- $\gamma$, MMP-9 and TNF- $\alpha$ ( $<2.5$-fold change).

Exclusively in co-culture, primary SCCs were exposed to IL-7 (53 pg/ml, SD 23), G-CSF (3,076, SD 330) and MMP-1 (24,473 pg/ml, SD 1,564).
CXCL-9 (208 pg/ml, SD 14) and IL-1ß (6.2 pg/ml, SD 1.2) were exclusively produced in co-culture of ADSCs and primary SCCs but not in mono-culture of both cell types.

\section{Migration}

The migration through the transwell pores could already be detected when ADSC, A431-SCCs, or primary SCCs were cultured alone; however, when co-cultured with A431-SCCs the migration of ADSC was significantly increased about $17 \%(P=0.012)$, while that of the A431SCCs was not changed compared to the mono-culture $(P>0.05)$ (Figure 4a). In co-culture with ADSCs the migratory capacity of the primary SCCs was also significantly increased by about $15 \%(P=0.009)$ while that of the ADSCs remained unchanged (Figure $4 \mathrm{~b}$ ). 

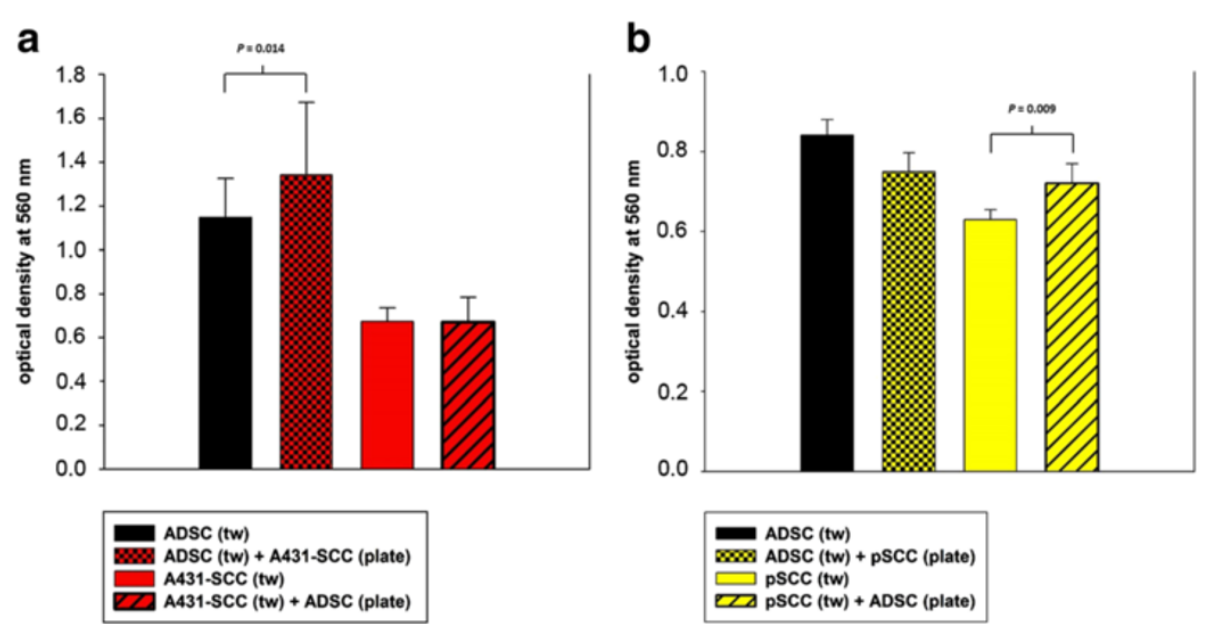

Figure 4 Migration assay. a) Migratory capacity of the ADSCs (black bar) and A431-SCCs (red bar) alone and in co-culture, measured as the level of optical density at $560 \mathrm{~nm}$, with a standard deviation (SD). When co-cultured with A431-SCCs (black bar with red checkerboard pattern) ADSCs showed a significantly higher migration as in mono-culture $(P=0.014)$. Co-culture of A431-SCCs with ADSCs (red bars with black diagonal slashes) does not lead to a significant change in the migratory properties of A431-SCCs $(P>0.05)$. b) Migratory capacity of the ADSCs (black bar) and pSCCs (yellow bar) alone and in co-culture, measured as the level of optical density at $560 \mathrm{~nm}$, with a SD. When co-cultured with pSCCs (black bar with yellow checkerboard pattern) ADSCs showed a higher migration as in mono-culture $(P>0.05)$. Co-culture of pSCCs with ADSCs (yellow bars with black diagonal slashes) resulted in a significantly increased migration of pSCCs $(P=0.009)$. ADSC, adipose tissue derived stem cells; pSCCs, primary squamous cell carcinoma cells; SCCs, squamous cell carcinoma cells.

\section{Invasion}

ADSCs and A431-SCCs showed invasive behavior by actively digesting the extracellular matrix blocking the transwell pores and migrating to the lower surface of the transwell inserts' floor. This was significantly increased by a mean of $33 \%$ in the co-cultures for ADSCs $(P=0.014)$ and significantly increased by a mean of $35 \%$ for SCCs $(P<0.001)$, respectively (Figure $5 \mathrm{a})$. When coculturing primary SCCs with ADSCs the invasive behavior of the primary SCCs was significantly increased by a mean of $33 \%$ compared to the culture of primary SCCs alone $(P=0.038)$. The invasive behavior of ADSCs in this context was not changed by co-culturing with primary SCCs (Figure 5b).

\section{Angiogenesis}

Tube formation could be detected after incubation of HUVEC cells with conditioned media from co-cultured ADSC-A431-SCCs and slightly from co-cultured ADSCspSCCs, and mono-cultured ADSCs or A431-SCCs. No significant angiogenesis could be detected when conditioned media from pSCC- or A431-SCC-mono-culture was added to the system (Figure 6).

\section{Discussion}

ADSCs are a promising future tool in skin regenerative medicine, providing many so far suggested positive effects, such as increasing the dermal collagen content, supporting neoangiogenesis or inhibiting melanin synthesis and the activity of skin matrix degrading enzymes [1,3-5,14]. These effects are mainly due to the paracrine activity of the transplanted stem cells, reflecting the reaction of the surrounding cells, such as dermal fibroblasts or melanocytes, towards secreted cytokines and growth factors. In vivo, however, there is always a risk of malignant cells being present in the vicinity of the transplanted ADSCs. These malignant cells would also be in direct contact with the released proteins, and thus, prone to be influenced by the ADSCs secretome. Nevertheless, research about the possible interactions of ADSCs and skin tumor cells is still not in the focus of most skin regeneration projects. The present study is the first to show that the co-culture of human SCCs and human ADSCs leads to a significant change in the gene expression profile of both cell types, as well as a remarkable change in the secreted protein levels. Additionally, ADSCs increased their migration towards SCCs, and invasiveness rose in both cell types, with the latter being an important indicator for a possible rise of local destruction and occurrence of metastases. Furthermore, some proteins, such as MMP-7, IL-1 $\beta$ or CXCL9, were exclusively produced in ADSC(p)SCC-co-culture, but not in mono-culture. These aforementioned changes in protein and gene expression strongly point towards important adverse biological consequences that may arise in case of the in vivo copresence of ADSCs and SCCs.

In co-culture the gene expression or protein synthesis of a couple of pro-angiogenic proteins, such as FGF-2, 

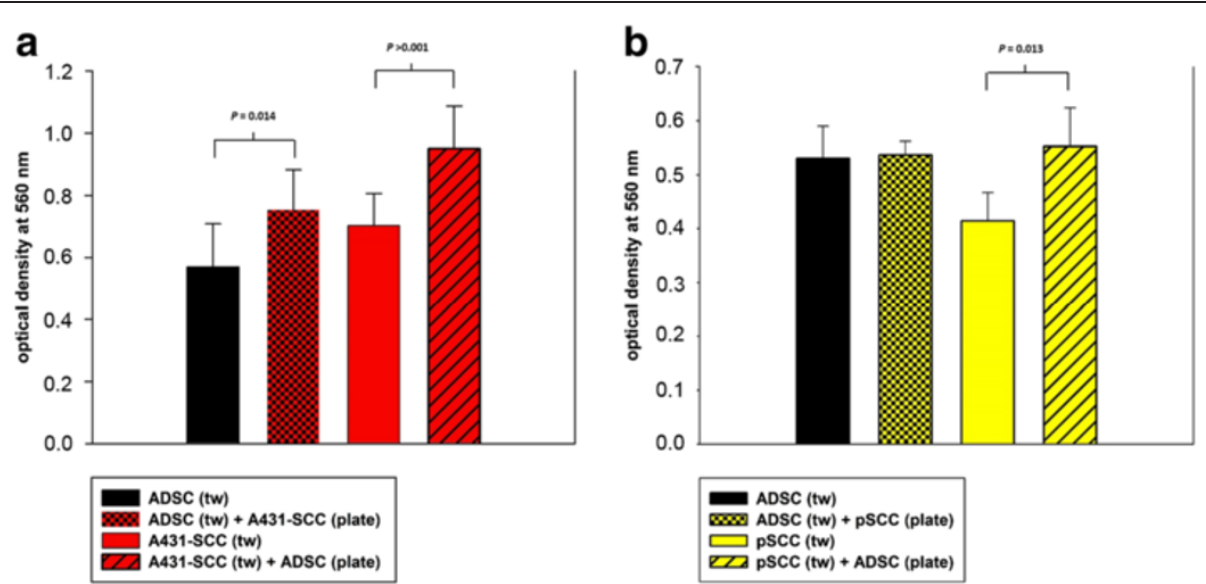

Figure 5 Invasion assay. a) Invasive behavior of ADSCs (black bar) and A431-SCCs (red bar) alone and in co-culture, measured as the level of optical density at $560 \mathrm{~nm}$ with a standard deviation (SD). When co-cultured with A431-SCCs (black bar with red checkerboard pattern) ADSCS showed a significantly higher invasive capacity as in mono-culture $(P=0.014)$. Co-culture of SCCs with ADSCs (red bars with black diagonal slashes) also leads to a significant increase in the invasive behavior of A431-SCCs $(P<0.001)$. b) Invasive behavior of ADSCs (black bar) and pSCCs (yellow bar) alone and in co-culture, measured as the level of optical density at $560 \mathrm{~nm}$, with a SD. When co-cultured with pSCCs (black bar with yellow checkerboard pattern) ADSCs did not significantly change their invasive capacity compared to mono-culture. Co-culture of pSCCs with ADSCs (yellow bars with black diagonal slashes), however, leads to a significant increase in the invasive behavior of pSCCS $(P=0.013)$. ADSC, adipose tissue derived stem cells; pSCCs, primary squamous cell carcinoma cells; SCCs, squamous cell carcinoma cells.

IL-8, VEGF, CCL2 and CXCL6, is strongly up-regulated in ADSCs and/or SCCs. They are all known to support neoangiogenesis by increased migration and mitosis of endothelial cells, formation of new capillaries and vessel fenestrations or inhibition of endothelial cell apoptosis [15-26]. By supplying nutrition, this is an important component of tumor growth. Fittingly, we found an increased angiogenic potential in ADSC-A431-SCC-coculture compared to respective mono-cultures in vitro. Several of these angiogenic proteins lead to an enhanced secretion of metalloproteinases and an increased MMPactivity, which not only facilitates neoangiogenesis, but also degradation of extracellular matrix and thereby invasive tumor growth. In contrast to that, the angiostatic CXCL-9 and CXCL10 [27] are down-regulated in coculture or only expressed at a very low level.

IL-6 gene expression is highly up-regulated in ADSCs co-cultured with A431- and primary SCCs and the IL-6 protein level significantly increased in the co-culture medium, too. IL-6 has been reported to be a proliferative factor for diverse tumor types in vivo [28-30], and elevated serum levels of IL-6 have been associated with key features of malignancy, cancer progression and a poor clinical outcome in different types of cancers [31-37]. Presumably, one part of these IL- 6 effects is achieved by increasing TWIST-expression, as well as stabilizing TWIST and inhibiting its degradation, thereby increasing cell motility and tumor progression [32]. TWIST1 encodes for the TWIST-related protein 1, a transcription factor, which acts as an oncogene in several cancers and has been shown to be involved in the development of resistance towards chemotherapeutic drugs and evading apoptosis [38]. When co-cultured with ADSCs TWIST1 was also significantly up-regulated in A431-SCCs cells in our experiment. TWIST1 plays a role in metastasis, presumably through up-regulation of MMP-expression and inhibition of tissue inhibitor of metalloproteinases-1 expression $[39,40]$. Indeed, the gene expression or protein synthesis of matrix metalloproteinases, such as MMP-1, $-2,-3$ or -7 , was highly up-regulated when ADSCs and A431- or primary SCCs were co-cultured. In fact, MMP-7 was solely produced in co-culture but not in mono-culture. MMPs contribute to the breakdown of extracellular matrix in a multitude of physiological and pathological processes (for example, connective tissue remodeling, wound repair and metastasis). We could show a corresponding significant increase in the invasive behavior of primary SCCs and A431-SCCs and ADSCs, in the co-culture. Altered MMP expression has already been linked with poor disease prognosis in different human cancers and enhanced cancer cell invasion [41,42]. In addition to that, the CTKS gene expression was up-regulated in co-cultured A431-SCCs. CTKS encodes for cathepsin $\mathrm{K}$, a cysteine protease with strong collagenolytic and elastolytic properties which is involved in extracellular matrix turnover $[43,44]$. CTKS up-regulation has been associated with tumor progression in squamous cell carcinomas of the skin [43].

Regarding the extracellular matrix (ECM), the expression of the fibronectin 1 gene $F N 1$ was slightly up-regulated 


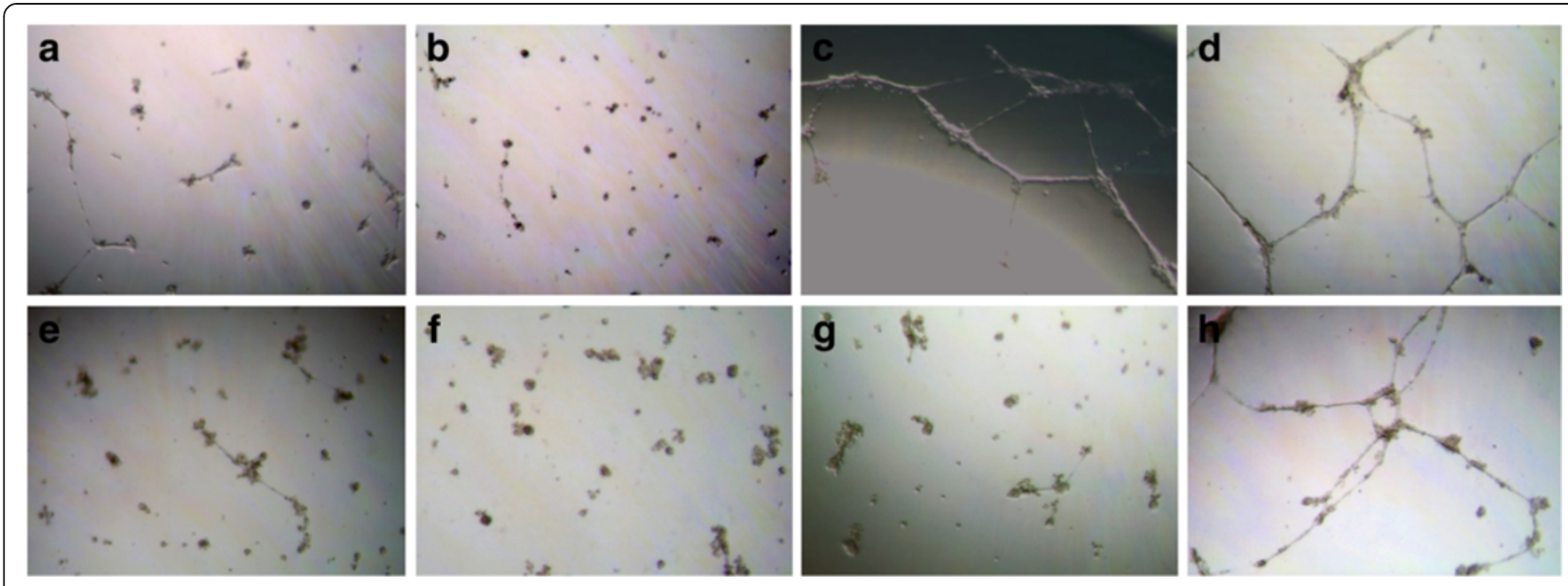

Figure 6 Induction of angiogenesis. Angiogenesis assay with incubation of HUVEC cells with conditioned media from mono-cultured ADSCs $(\mathbf{a}, \mathbf{e})$, A431-SCCS (b), pSCCS (f), co-cultured ADSC-A431-SCCS (c), and co-cultured ADSCs-pSCCs (g). Controls (d, h) were induced with PMA. Tube formation could be detected with conditioned media from co-cultured ADSC-A431-SCCs, slightly from co-cultured ADSCs-pSCCs, and mono-cultured ADSCS or A431-SCCs. No significant angiogenesis could be detected when conditioned media from pSCC- or A431-SCC-monoculture was added to the system. ADSC, adipose tissue derived stem cells; HUVEC, human umbilical vein endothelial cells; PMA, phorbol 12-myristate 13-acetate; pSCCs, primary squamous cell carcinoma cells; SCCs, squamous cell carcinoma cells.

in co-cultured A431-SCCs. High FN1 expression or upregulation in tumor cells has been associated with radioresistance, tumor progression and metastatic outgrowth [45-47]. Presumably, together with other extracellular matrix proteins, fibronectin forms a complex network around the tumor cells, regulating cell adhesion, migration and proliferation of tumor cells, fibroblasts and endothelial cells $[48,49]$. Integrins can bind fibronectin and are crucial in different tumor-associated processes, such as tumor cell growth, angiogenesis and metastasis. Co-culture strongly up-regulated the ITGA2B (integrin alpha 2 beta)-expression in ADSCs and ITGB3 (integrin beta 3) gene expression in A431-SCCs. Increased ITGB3 expression has been linked to an increase in migration and invasion, as well as a more aggressive phenotype of tumor cells, a progressed tumor grade and a poor prognosis [50,51].

Furthermore, ADSC-SCC-co-culture resulted in a very strong up-regulation of the gene expression of CSF-2 and -3 which resulted in a corresponding extraordinary increase in G-CSF and a moderate increase in GM-CSF concentration in the co-culture media. In general, GCSF is associated with the stimulation of granulocytes and the proliferation of immature hematopoietic precursor cells during inflammatory responses. Tumor-derived G-CSF, however, has been demonstrated to be able to enhance tumor growth by inducing myeloid-derived suppressor cells, which suppress innate and adaptive immunity [52]. Thus, the increase in G-CSF by coculturing ADSCs with SCCs might be associated with an increased tumor growth in vivo. Enhanced GMCSF-levels in tumors are associated with a reduced cell proliferation but an increased migratory capacity, an increased tumor cell invasion by elevating MMP expression, and a higher vessel density [53]. This might be an explanation for the significantly reduced proliferation in co-cultured primary SCCs in our experiment.

Cancers often arise in association with a long lasting chronic inflammation [54]. High expression of some interleukins, such as IL- $1 \alpha$ and IL- $1 \beta$, has been associated with a more aggressive tumor type and poor prognosis [55-57]. ADSCs-SCCs-co-culture - both, with A431SCCs and primary SCCs, led to a strong increase in IL$1 \alpha$ and $\beta$ gene expression in ADSCs. IL- $1 \beta$ could only be detected in co-culture and not in mono-culture of ADSCs or primary SCCs. Both proteins, IL- $1 \alpha$ and $-\beta$, have been implicated in tumor progression by inducing the expression of angiogenic and metastatic genes, cytokines and growth factors, such as MMPs, VEGF, IL-6 and $8, \mathrm{CCl} 2, \mathrm{CCL} 7, \mathrm{TNF} \alpha$ and TGF $\beta$ [58-60]. Importantly, IL1- $\beta$ also stimulates an increase in prostaglandin E2 production through cyclooxygenase-2 (COX-2) induction. The highly up-regulated PTGS2 gene in cocultured ADSCs and also in A431-SCCs, encoding for COX-2, further supports this. All essential steps of malignant tumor progression, such as mutagenesis, mitogenesis, angiogenesis, reduced apoptosis, metastasis and immunosuppression, are associated with prostaglandin 2 [61]. Furthermore, it has been shown that infiltrates of immune cells and expression of inflammatory mediators, for example, cytokines and chemokines, are an important part of the tumor milieu and substantially contribute to tumor development and progression [62]. In this context, it is important to see that there is a robust up- 
regulation of different cytokines and chemokines, for example, CCL2, CCL3, CCL4, CCL5, CCL7, CCL8, CCL13, CCL20, CCL28, CXCL1, CXCL2, CXCL3, CXL5, CXCL6, CXCL11, CXCL12 and CXCL14 in ADSCs co-cultured with primary or A431-SCCs. CXCL9 expression can only be detected in co-culture. In tumors these chemokines attract special leukocyte/monocyte subpopulations - for example, tumor associated macrophages - which can promote tumor growth and metastasis by stimulating angiogenesis, ECM-degradation and tumor cell proliferation [63-66]. High numbers of these macrophages present at the tumor site have been associated with poor prognosis and disease progression [67]. CCL2 additionally promotes epithelial to mesenchymal transition and is linked to cancer cell migration and cancer progression [65,68]. In line with that, E-Cadherin was strongly down-regulated and $\mathrm{N}$-Cadherin strongly up-regulated in co-cultured A431SCCs, suggesting an epithelial-mesenchymal transition. E-Cadherin is an important cell-cell adhesion molecule in epithelial cells. Its down-regulation has not only been implicated in epithelial-mesenchymal transition, but also in an increase in cellular motility, invasion and metastasis. There is an inverse correlation among E-cadherin levels, tumor grade and patient mortality rates [69].

Different $\mathrm{C}-\mathrm{C}$ motif ligand-chemokines (CCL) and C$\mathrm{X}-\mathrm{C}$ motif ligand chemokines (CXCL), such as CCL2, CCL7, CXCL1 and CXCL6, are also potent stimulators of pro-malignant features, such as tumor cell proliferation, migration and invasion, as well as angiogenesis. They promote tumor growth, facilitate metastasis, and high serum levels are associated with a poor outcome $[60,66,70-73]$. However, it is important to say that posttranscriptional modifications are common for many chemokines, affecting their biological function [74]. Thus, the up-regulation of their gene expression does not necessarily lead to a one-to-one change in protein activity and in vivo function.

In addition, HGF gene expression was strongly increased in co-cultured A431-SCCs, and also primary SCCs were exposed to a highly increased hepatocyte growth factor (HGF) level in co-culture compared to monoculture, due to high expression of HGF by ADSCs. HGF is known to be a potent angiogenic factor and to be associated with a more advanced tumor stage in different malignancies in vivo [75]. Furthermore, it has been demonstrated that HGF significantly increases the migration and invasion of esophageal SCCs in vitro, and that it is a major component of tumor progression induced by tumor-associated fibroblasts [76,77]. Thus, an increased HGF level in the ADSC-SCCs microenvironment, as shown in our experiment, might also promote tumor progression in an in vivo setting.

Other important genes were also up-regulated in co-cultured ADSCs: LYPD3, WISP-1, TLR-2, and SERPINE-
1. LYPD3, encoding for the Ly6/PLAUR domain-containing membrane protein 3 , has been shown to be down-regulated upon transition to dysplasia and carcinoma in situ, and being up-regulated again at the invasive front and in local lymph node metastasis of esophageal squamous cell carcinomas $[78,79]$. The WISP-1 gene encodes the Wnt-induced secreted protein-1, which has been shown to enhance tumor cell migration by increasing MMP-2 expression, and to inhibit anti-tumor immunity by blocking the response of immune cells to IL-12. Furthermore, it has been associated with a poor prognosis in certain tumor types [80-82]. In addition, also, the TLR-2 (Toll-like receptor-2) has been associated with increased tumor progression and metastasis, as well as tumor angiogenesis [83].

SERPINE-1 encodes for the plasminogen activator inhibitor-1 (PAI-1) which is thought to facilitate tumor invasion by controlling the peritumor proteolytic microenvironment, regulating cell adhesion and migration, and stabilizing early capillary vessel structures. Elevated PAI-1 levels have been associated with a poor prognosis and a reduced disease-free survival in various malignancies $[84,85]$.

Two other genes were also up-regulated in ADSCs cocultured with A431 or pSCCs, respectively, NR4A3 and KISS1R. NR4A3 encodes for the orphan nuclear receptor $N O R-1$, an early immediate response gene, which among others is involved in cell growth and survival, apoptosis, glucose and lipid metabolism, and inflammation [86-88]. $K I S S-1 R$ encodes for the KiSS1-derived peptide receptor, a G-protein-coupled receptor which is known to play multiple roles in cancer development and metastasis [89]. For both proteins, their distinct functions are discussed controversially in different tumor types.

The expression of the CCND2 gene, encoding for cyclin D2, was up-regulated in primary SCCs co-cultured with ADSCs. Cyclin D2 plays an important role in the cell cycle at the transition from G1- to S-phase. High expression of CCND2 in vitro has been strongly associated with a more invasive SCC cell type in vivo and malignant progression $[90,91]$.

Besides that, the primary SCCs gene expression did not seem to be much altered by co-culturing with ADSCs. Additionally, if cultured on the plate of the transwell system, co-culture of ADSCs and pSCCs significantly lowered the proliferation of both cell types. However, this should be interpreted cautiously, as it is not a sign of lack of interaction between or a hint towards a safe coexistence of these two cell types. The reduced cellular proliferation of primary SCCs determined under certain in vitro culture conditions might be a result of the increased GM-CSF-levels [53], a temporary effect or reflect a lack of supplemented nutrients in the in vitro situation. A risk of increased malignant features of SCCs in close 
vicinity of ADSCs is already suggested by the fact that the tumor cells are exposed to a new or more potent cocktail of cytokines, growth factors and matrix degrading enzymes secreted by the ADSCs. In line with that, we could show that the co-culture with ADSCs significantly increased the migration and invasion of primary SCCs in vitro.

The present study is first to show numerous interactions of ADSCs and a well-known and often used SCC cell line as well as primary SCCs in vitro. The results intensely point to clinically relevant consequences, such as an increase in tumor growth and earlier or more disseminated metastasis. Our results strongly support the hypothesis that there is an interaction between ADSCs and SCCs with potentially detrimental consequences for patients. To clarify the, in part, contradictory results and to get the necessary further insight into the far more complex situation in vivo, we are currently performing in vivo experiments in a rodent model. Nonetheless, our current results already need to fuel a necessary discussion about the safety of ADSC-based therapies, particularly in the skin.

\section{Conclusion}

In summary, ADSCs significantly affect the multiple malignant properties of SCCs, such as invasion, gene expression and protein synthesis in vitro. Thereby ADSCs may strongly increase the risk of squamous cell carcinoma tumor growth and metastasis in vivo. Therefore, it is crucial to rigorously screen all patients for premalignant lesions prior to the injection of fat, stem cellaugmented fat or isolated ADSCs in the skin or adjacent tissues to avoid a potential co-localization of ADSCs and SCCs. Informed consent of patients to such procedures will need to include the explanation of an increased risk of developing a malignant skin condition or the faster growth and dissemination of a possibly pre-existing skin cancer.

\section{Additional file}

Additional file 1: Table S1. A) Co-culture of ADSCs and A431-SCC-cell line - Part 1. Minor changes in the gene expression of ADSCS - Part 2. Minor changes in the gene expression of A431-SCCs. B) Co-culture of ADSCs and primary SCCs. Part 1. Minor changes in the gene expression of ADSCs. Part 2. Changes in the gene expression of primary SCCs. Table S1 Part A. Minor changes in the gene expression levels of ADSCs and A431-SCCs in co-culture compared to mono-culture. GUSB was used as referring housekeeping-gene. Only changes of 2.5-fold or higher are displayed. Part 1 displays the changes in the gene expression levels of ADSCs. Part 2 shows the changes in the gene expression levels of A431-SCCs. Arrows mark an up- $(\uparrow)$ or down-regulation $(\downarrow)$ of the gene expression compared to the referring mono-culture. Table S1 Part B. Minor changes in the gene expression levels of ADSCs and pSCCs in co-culture compared to mono-culture. GUSB was used as referring housekeeping-gene. Only changes of 2.5 -fold or higher are displayed. Part 1 displays the changes in the gene expression levels of ADSCs. Part
2 shows the changes in the gene expression levels of pSCCs. Arrows mark an up- $(\uparrow)$ or down-regulation $(\downarrow)$ of the gene expression compared to the referring mono-culture.

\section{Abbreviations}

ADSCs: Adipose tissue-derived stem cells; CCL: C-C motif ligandchemokines; CEACAM-1: Carcinoembryonic antigen cell adhesion molecule; COX-2: Cyclooxygenase-2; CT: Cycle threshold; CXCL: C-X-C motif ligand chemokines; ECM: Extracellular matrix; EMT: Epithelial-mesenchymaltransition; EPCAM: Epithelial cell adhesion molecule; HGF: Hepatocyte growth factor; HUVEC: Human umbilical vein endothelial cells;

IL: Interleukin; ITGB3: Integrin beta 3; MMPs: Matrix metalloproteinases; PMA: Phorbol 12-myristate 13-acetate; pSCCs: primary squamous cell carcinoma cells; SCCs: Squamous cell carcinoma cells; SD: Standard deviation; TLR-2: Toll-like receptor-2.

\section{Competing interests}

The authors declare that they have no competing interests.

\section{Authors' contributions}

EK conceived of the study, coordinated the study, performed the statistical analysis and drafted the manuscript. FG drafted the manuscript, and helped in performing the statistical analysis and the interpretation of the data. FP carried out the flow cytometry and cell differentiation. UL isolated and cultured the cells, and participated in the analysis of gene expression. GG conceived of the study. VD carried out the gene expression analysis and the protein measurements. All authors read and approved the final version of the manuscript.

\section{Acknowledgments}

This study was financially supported by the Dietmar Hopp Foundation, Walldorf, Germany. We would like to thank Dr. Inka Zoernig, Prof. Dr. Holger Sültmann and their group members for technical assistance with the multiplex protein analysis.

\section{Author details}

${ }^{1}$ Clinic for Plastic and Reconstructive Surgery, Aesthetic and Preventive Medicine at Heidelberg University Hospital - ETHIANUM, Voßstraße 6, 69115 Heidelberg, Germany. ${ }^{2}$ Department of Cardiology, University of Frankfurt, Theodor-Stern-Kai 7, 60590 Frankfurt, Germany.

Received: 2 September 2013 Revised: 13 March 2013

Accepted: 22 April 2014 Published: 12 May 2014

\section{References}

1. Kim WS, Park BS, Park SH, Kim HK, Sung JH: Antiwrinkle effect of adipose-derived stem cell: activation of dermal fibroblast by secretory factors. J Dermatol Sci 2009, 53:96-102.

2. Kim WS, Park BS, Sung JH: The wound-healing and antioxidant effects of adipose-derived stem cells. Expert Opin Biol Ther 2009, 9:879-887.

3. Kim WS, Park BS, Sung JH: Protective role of adipose-derived stem cells and their soluble factors in photoaging. Arch Dermatol Res 2009, 301:329-336.

4. Kim WS, Park SH, Ahn SJ, Kim HK, Park JS, Lee GY, Kim KJ, Whang KK, Kang SH, Park BS, Sung JH: Whitening effect of adipose-derived stem cells: a critical role of TGF-beta 1. Biol Pharm Bull 2008, 31:606-610.

5. Kim JH, Jung M, Kim HS, Kim YM, Choi EH: Adipose-derived stem cells as a new therapeutic modality for ageing skin. Exp Dermatol 2011, 20:383-387.

6. Donnenberg VS, Zimmerlin L, Rubin JP, Donnenberg AD: Regenerative therapy after cancer: what are the risks? Tissue Eng Part B Rev 2010, 16:567-575.

7. Zimmerlin L, Donnenberg AD, Rubin JP, Basse P, Landreneau RJ, Donnenberg VS: Regenerative therapy and cancer: in vitro and in vivo studies of the interaction between adipose-derived stem cells and breast cancer cells from clinical isolates. Tissue Eng Part A 2011, 17:93-106.

8. Cirri $P$, Chiarugi $P$ : Cancer associated fibroblasts: the dark side of the coin. Am J Cancer Res 2011, 1:482-497.

9. Lomas A, Leonardi-Bee J, Bath-Hextall F: A systematic review of worldwide incidence of nonmelanoma skin cancer. Br J Dermatol 2012, 166:1069-1080. 
10. Hauner H, Entenmann G, Wabitsch M, Gaillard D, Ailhaud G, Negrel R, Pfeiffer EF: Promoting effect of glucocorticoids on the differentiation of human adipocyte precursor cells cultured in a chemically defined medium. J Clin Invest 1989, 84:1663-1670.

11. Ramirez-Zacarias JL, Castro-Munozledo F, Kuri-Harcuch W: Quantitation of adipose conversion and triglycerides by staining intracytoplasmic lipids with Oil red O. Histochemistry 1992, 97:493-497.

12. Dominici M, Le Blanc K, Mueller I, Slaper-Cortenbach I, Marini F, Krause D, Deans R, Keating A, Prockop D, Horwitz E: Minimal criteria for defining multipotent mesenchymal stromal cells. The International Society for Cellular Therapy position statement. Cytotherapy 2006, 8:315-317.

13. Mitchell JB, Mclntosh K, Zvonic S, Garrett S, Floyd ZE, Kloster A, Di Halvorsen Y, Storms RW, Goh B, Kilroy G, Wu X, Gimble JM: Immunophenotype of human adipose-derived cells: temporal changes in stromal-associated and stem cell-associated markers. Stem Cells 2006, 24:376-385.

14. Heo SC, Jeon ES, Lee IH, Kim HS, Kim MB, Kim JH: Tumor necrosis factoralpha-activated human adipose tissue-derived mesenchymal stem cells accelerate cutaneous wound healing through paracrine mechanisms. J Invest Dermatol 2011, 131:1559-1567.

15. Hamed EA, Zakhary MM, Maximous DW: Apoptosis, angiogenesis, inflammation, and oxidative stress: basic interactions in patients with early and metastatic breast cancer. J Cancer Res Clin Oncol 2012, 138:999-1009.

16. Lai $Y$, Liu XH, Zeng Y, Zhang Y, Shen Y, Liu Y: Interleukin-8 induces the endothelial cell migration through the Rac 1/RhoA-p38MAPK pathway. Eur Rev Med Pharmacol Sci 2012, 16:630-638.

17. Shen XH, Xu SJ, Jin CY, Ding F, Zhou YC, Fu GS: Interleukin-8 prevents oxidative stress-induced human endothelial cell senescence via telomerase activation. Int Immunopharmacol 2013, 16:261-267.

18. Dewing D, Emmett M, Pritchard Jones $R$ : The roles of angiogenesis in malignant melanoma: trends in basic science research over the last 100 years. ISRN Oncol 2012, 2012:546927.

19. Ferrara N: Vascular endothelial growth factor and the regulation of angiogenesis. Recent Prog Horm Res 2000, 55:15-35. discussion 35-36.

20. Eisma RJ, Spiro JD, Kreutzer DL: Role of angiogenic factors: coexpression of interleukin- 8 and vascular endothelial growth factor in patients with head and neck squamous carcinoma. Laryngoscope 1999, 109:687-693.

21. Chikazawa M, Inoue K, Fukata S, Karashima T, Shuin T: Expression of angiogenesis-related genes regulates different steps in the process of tumor growth and metastasis in human urothelial cell carcinoma of the urinary bladder. Pathobiology 2008, 75:335-345.

22. Charalambous C, Pen LB, Su YS, Milan J, Chen TC, Hofman FM: Interleukin-8 differentially regulates migration of tumor-associated and normal human brain endothelial cells. Cancer Res 2005, 65:10347-10354

23. Boldrini L, Gisfredi S, Ursino S, Lucchi M, Mussi A, Basolo F, Pingitore R, Fontanini G: Interleukin-8 in non-small cell lung carcinoma: relation with angiogenic pattern and p53 alterations. Lung Cancer 2005, 50:309-317.

24. Beckermann BM, Kallifatidis G, Groth A, Frommhold D, Apel A, Mattern J, Salnikov AV, Moldenhauer G, Wagner W, Diehlmann A, Saffrich R, Schubert M, Ho AD, Giese N, Buchler MW, Friess H, Buchler P, Herr I: VEGF expression by mesenchymal stem cells contributes to angiogenesis in pancreatic carcinoma. Br J Cancer 2008, 99:622-631.

25. Ueno T, Toi M, Saji H, Muta M, Bando H, Kuroi K, Koike M, Inadera H, Matsushima K: Significance of macrophage chemoattractant protein-1 in macrophage recruitment, angiogenesis, and survival in human breast cancer. Clin Cancer Res 2000, 6:3282-3289.

26. Gijsbers K, Gouwy M, Struyf S, Wuyts A, Proost P, Opdenakker G, Penninckx F, Ectors N, Geboes K, Van Damme J: GCP-2/CXCL6 synergizes with other endothelial cell-derived chemokines in neutrophil mobilization and is associated with angiogenesis in gastrointestinal tumors. Exp Cell Res 2005, 303:331-342.

27. Rosenkilde MM, Schwartz TW: The chemokine system - a major regulator of angiogenesis in health and disease. APMIS 2004, 112:481-495.

28. Yamaji H, lizasa T, Koh E, Suzuki M, Otsuji M, Chang H, Motohashi S, Yokoi S, Hiroshima K, Tagawa M, Nakayama T, Fujisawa T: Correlation between interleukin 6 production and tumor proliferation in non-small cell lung cancer. Cancer Immunol Immunother 2004, 53:786-792.

29. Hartman ZC, Poage GM, den Hollander P, Tsimelzon A, Hill J, Panupinthu N, Zhang Y, Mazumdar A, Hilsenbeck SG, Mills GB, Brown PH: Growth of triple-negative breast cancer cells relies upon coordinate autocrine expression of the proinflammatory cytokines IL- 6 and IL-8. Cancer Res $2013,73: 3470-3480$
30. Hartman ZC, Yang XY, Glass O, Lei G, Osada T, Dave SS, Morse MA, Clay TM, Lyerly HK: HER2 overexpression elicits a proinflammatory IL-6 autocrine signaling loop that is critical for tumorigenesis. Cancer Res 2011 71:4380-4391.

31. Gupta N, Goswami B, Mittal P: Effect of standard anthracycline based neoadjuvant chemotherapy on circulating levels of serum IL-6 in patients of locally advanced carcinoma breast - a prospective study. Int J Surg 2012, 10:638-640.

32. Su YW, Xie TX, Sano D, Myers JN: IL-6 stabilizes Twist and enhances tumor cell motility in head and neck cancer cells through activation of casein kinase 2. PLoS One 2011, 6:e19412.

33. Yamada D, Kobayashi S, Wada H, Kawamoto K, Marubashi S, Eguchi H, Ishii H, Nagano H, Doki Y, Mori M: Role of crosstalk between interleukin-6 and transforming growth factor-beta 1 in epithelial-mesenchymal transition and chemoresistance in biliary tract cancer. Eur J Cancer 2013, 49:1725-1740

34. Lippitz BE: Cytokine patterns in patients with cancer: a systematic review. Lancet Oncol 2013, 14:e218-e228.

35. Touboul C, Lis R, Al Farsi H, Raynaud CM, Warfa M, Althawadi H, Mery E, Mirshahi M, Rafii A: Mesenchymal stem cells enhance ovarian cancer cell infiltration through IL6 secretion in an amniochorionic membrane based 3D model. J Trans/ Med 2013, 11:28.

36. Chen CJ, Sung WW, Lin YM, Chen MK, Lee CH, Lee H, Yeh KT, Ko JL: Gender difference in the prognostic role of interleukin 6 in oral squamous cell carcinoma. PLoS One 2012, 7:e50104.

37. Wang X, Lee SO, Xia S, Jiang Q, Luo J, Li L, Yeh S, Chang C: Endothelial cells enhance prostate cancer metastasis via IL-6- > androgen receptor- > TGF-beta- > MMP-9 signals. Mol Cancer Ther 2013, 12:1026-1037.

38. Low-Marchelli JM, Ardi VC, Vizcarra EA, van Rooijen N, Quigley JP, Yang J: Twist1 induces CCL2 and recruits macrophages to promote angiogenesis. Cancer Res 2013, 73:662-671.

39. Okamura H, Yoshida K, Haneji T: Negative regulation of TIMP1 is mediated by transcription factor TWIST1. Int J Oncol 2009, 35:181-186.

40. Yang J, Mani SA, Donaher JL, Ramaswamy S, Itzykson RA, Come C, Savagner P, Gitelman I, Richardson A, Weinberg RA: Twist, a master regulator of morphogenesis, plays an essential role in tumor metastasis. Cell 2004, 117:927-939.

41. Bekes EM, Schweighofer B, Kupriyanova TA, Zajac E, Ardi VC, Quigley JP, Deryugina El: Tumor-recruited neutrophils and neutrophil TIMP-free MMP-9 regulate coordinately the levels of tumor angiogenesis and efficiency of malignant cell intravasation. Am J Pathol 2011, 179:1455-1470.

42. Davidson B, Goldberg I, Gotlieb WH, Kopolovic J, Ben-Baruch G, Nesland JM, Reich $R$ : The prognostic value of metalloproteinases and angiogenic factors in ovarian carcinoma. Mol Cell Endocrinol 2002, 187:39-45.

43. Ishida M, Kojima F, Okabe H: Cathepsin K expression in basal cell carcinoma. J Eur Acad Dermatol Venereol 2013, 27:e128-e130.

44. Xie L, Moroi Y, Hayashida S, Tsuji G, Takeuchi S, Shan B, Nakahara T, Uchi H, Takahara M, Furue M: Cathepsin K-upregulation in fibroblasts promotes matrigel invasive ability of squamous cell carcinoma cells via tumor-derived IL-1alpha. J Dermatol Sci 2011, 61:45-50.

45. Jerhammar F, Ceder R, Garvin S, Grenman R, Grafstrom RC, Roberg K Fibronectin 1 is a potential biomarker for radioresistance in head and neck squamous cell carcinoma. Cancer Biol Ther 2010, 10:1244-1251.

46. Waalkes S, Atschekzei F, Kramer MW, Hennenlotter J, Vetter G, Becker JU, Stenzl A, Merseburger AS, Schrader AJ, Kuczyk MA, Serth J: Fibronectin 1 mRNA expression correlates with advanced disease in renal cancer. BMC Cancer 2010, 10:503.

47. Mikheeva SA, Mikheev AM, Petit A, Beyer R, Oxford RG, Khorasani L, Maxwell JP, Glackin CA, Wakimoto H, Gonzalez-Herrero I, Sanchez-Garcia I, Silber JR, Horner PJ, Rostomily RC: TWIST1 promotes invasion through mesenchymal change in human glioblastoma. Mol Cancer 2010, 9:194

48. Meeh PF, Farrell CL, Croshaw R, Crimm H, Miller SK, Oroian D, Kowli S, Zhu J, Carver W, Wu W, Pena E, Buckhaults PJ: A gene expression classifier of node-positive colorectal cancer. Neoplasia 2009, 11:1074-1083.

49. Soikkeli J, Podlasz P, Yin M, Nummela P, Jahkola T, Virolainen S, Krogerus L, Heikkila P, von Smitten K, Saksela O, Holtta E: Metastatic outgrowth encompasses COL-I, FN1, and POSTN up-regulation and assembly to fibrillar networks regulating cell adhesion, migration, and growth. Am J Pathol 2010, 177:387-403.

50. Schittenhelm J, Schwab El, Sperveslage J, Tatagiba M, Meyermann R, Fend F Goodman SL, Sipos B: Longitudinal expression analysis of alphav integrins 
in human gliomas reveals upregulation of integrin alphavbeta3 as a negative prognostic factor. J Neuropathol Exp Neurol 2013, 72:194-210.

51. Lei Y, Huang K, Gao C, Lau QC, Pan H, Xie K, Li J, Liu R, Zhang T, Xie N, Nai HS, Wu H, Dong Q, Zhao X, Nice EC, Huang C, Wei Y: Proteomics identification of ITGB3 as a key regulator in reactive oxygen species-induced migration and invasion of colorectal cancer cells. Mol Cell Proteomics 2011, 0:M110 005397.

52. Waight JD, Hu Q, Miller A, Liu S, Abrams SI: Tumor-derived G-CSF facilitates neoplastic growth through a granulocytic myeloid-derived suppressor cell-dependent mechanism. PLoS One 2011, 6:e27690.

53. Gutschalk CM, Yanamandra AK, Linde N, Meides A, Depner S, Mueller MM: GM-CSF enhances tumor invasion by elevated MMP-2, -9 , and -26 expression. Cancer Med 2013, 2:117-129.

54. Demaria S, Pikarsky E, Karin M, Coussens LM, Chen YC, El-Omar EM, Trinchieri G, Dubinett SM, Mao JT, Szabo E, Krieg A, Weiner GJ, Fox BA, Coukos G, Wang E, Abraham RT, Carbone M, Lotze MT: Cancer and inflammation: promise for biologic therapy. J Immunother 2010, 33:335-351.

55. Sethi G, Shanmugam MK, Ramachandran L, Kumar AP, Tergaonkar V: Multifaceted link between cancer and inflammation. Biosci Rep 2012, 32:1-15.

56. Liu Q, Russell MR, Shahriari K, Jernigan DL, Lioni MI, Garcia FU, Fatatis A: Interleukin-1beta promotes skeletal colonization and progression of metastatic prostate cancer cells with neuroendocrine features. Cancer Res 2013, 73:3297-3305.

57. Landvik NE, Hart K, Haugen A, Zienolddiny S: Functional analysis of a lung cancer risk haplotype in the IL1B gene regulatory region. J Hum Genet 2012, 57:747-752.

58. Lewis AM, Varghese $\mathrm{S}, \mathrm{Xu}$ H, Alexander HR: Interleukin-1 and cancer progression: the emerging role of interleukin-1 receptor antagonist as a novel therapeutic agent in cancer treatment. J Trans/ Med 2006, 4:48

59. Nozaki S, Sledge GW Jr, Nakshatri H: Cancer cell-derived interleukin 1alpha contributes to autocrine and paracrine induction of pro-metastatic genes in breast cancer. Biochem Biophys Res Commun 2000, 275:60-62.

60. Jung DW, Che ZM, Kim J, Kim K, Kim KY, Williams D, Kim J: Tumor-stromal crosstalk in invasion of oral squamous cell carcinoma: a pivotal role of CCL7. Int J Cancer 2010, 127:332-344.

61. Harris RE: Cyclooxygenase-2 (cox-2) and the inflammogenesis of cancer. Subcell Biochem 2007, 42:93-126.

62. Sheng KC, Wright MD, Apostolopoulos V: Inflammatory mediators hold the key to dendritic cell suppression and tumor progression. Curr Med Chem 2011, 18:5507-5518.

63. Chen D, Jiang R, Mao C, Shi L, Wang S, Yu L, Hu Q, Dai D, Xu H: Chemokine/chemokine receptor interactions contribute to the accumulation of Th17 cells in patients with esophageal squamous cell carcinoma. Hum Immunol 2012, 73:1068-1072.

64. Marsigliante S, Vetrugno C, Muscella A: CCL20 induces migration and proliferation on breast epithelial cells. J Cell Physio/ 2013, 228:1873-1883.

65. Ben-Baruch A: The multifaceted roles of chemokines in malignancy. Cancer Metastasis Rev 2006, 25:357-371.

66. Acharyya S, Oskarsson T, Vanharanta S, Malladi S, Kim J, Morris PG, ManovaTodorova K, Leversha M, Hogg N, Seshan VE, Norton L, Brogi E, Massague J: A CXCL1 paracrine network links cancer chemoresistance and metastasis. Cell 2012, 150:165-178.

67. Kurago ZB, Lam-ubol A, Stetsenko A, De La Mater C, Chen Y, Dawson DV: Lipopolysaccharide-squamous cell carcinoma-monocyte interactions induce cancer-supporting factors leading to rapid STAT3 activation. Head Neck Pathol 2008, 2:1-12.

68. Lugassy C, Torres-Munoz JE, Kleinman HK, Ghanem G, Vernon S, Barnhill RL: Overexpression of malignancy-associated laminins and laminin receptors by angiotropic human melanoma cells in a chick chorioallantoic membrane model. J Cutan Pathol 2009, 36:1237-1243.

69. Cavallaro U, Christofori G: Cell adhesion and signalling by cadherins and lg-CAMs in cancer. Nat Rev Cancer 2004, 4:118-132.

70. Cho YB, Lee WY, Choi SJ, Kim J, Hong HK, Kim SH, Choi YL, Kim HC, Yun SH, Chun HK, Lee KU: CC chemokine ligand 7 expression in liver metastasis of colorectal cancer. Oncol Rep 2012, 28:689-694.

71. Hwang TL, Lee LY, Wang CC, Liang Y, Huang SF, Wu CM: CCL7 and CCL21 overexpression in gastric cancer is associated with lymph node metastasis and poor prognosis. World J Gastroenterol 2012, 18:1249-1256.

72. Divella R, Daniele A, Savino E, Palma F, Bellizzi A, Giotta F, Simone G, Lioce M, Quaranta M, Paradiso A, Mazzocca A: Circulating levels of transforming growth factor-betaeta (TGF-beta) and chemokine (C-X-C motif) ligand-1
(CXCL1) as predictors of distant seeding of circulating tumor cells in patients with metastatic breast cancer. Anticancer Res 2013, 33:1491-1497.

73. Van Coillie E, Van Aelst I, Wuyts A, Vercauteren R, Devos R, De Wolf-Peeters C, Van Damme J, Opdenakker G: Tumor angiogenesis induced by granulocyte chemotactic protein-2 as a countercurrent principle. Am J Pathol 2001, 159:1405-1414.

74. Mortier A, Gouwy M, Van Damme J, Proost P: Effect of posttranslational processing on the in vitro and in vivo activity of chemokines. Exp Cell Res 2011, 317:642-654

75. Xu Z, Wang S, Wu M, Zeng W, Wang X, Dong Z: TGFbeta1 and HGF protein secretion by esophageal squamous epithelial cells and stromal fibroblasts in oesophageal carcinogenesis. Oncol Lett 2013, 6:401-406.

76. Ren Y, Cao B, Law S, Xie Y, Lee PY, Cheung L, Chen Y, Huang X, Chan HM, Zhao P, Luk J, Vande Woude G, Wong J: Hepatocyte growth factor promotes cancer cell migration and angiogenic factors expression: a prognostic marker of human esophageal squamous cell carcinomas. Clin Cancer Res 2005, 11:6190-6197.

77. Grugan KD, Miller CG, Yao Y, Michaylira CZ, Ohashi S, Klein-Szanto AJ, Diehl JA, Herlyn M, Han M, Nakagawa H, Rustgi AK: Fibroblast-secreted hepatocyte growth factor plays a functional role in esophageal squamous cell carcinoma invasion. Proc Natl Acad Sci U S A 2010, 107:11026-11031.

78. Paret C, Bourouba M, Beer A, Miyazaki K, Schnolzer M, Fiedler S, Zoller M: Ly6 family member C4.4A binds laminins 1 and 5, associates with galectin-3 and supports cell migration. Int J Cancer 2005, 115:724-733.

79. Hansen LV, Laerum OD, Illemann M, Nielsen BS, Ploug M: Altered expression of the urokinase receptor homologue, C4.4A, in invasive areas of human esophageal squamous cell carcinoma. Int J Cancer 2008, 122:734-741.

80. Kulkarni YM, Chambers E, McGray AJ, Ware JS, Bramson JL, Klinke DJ 2nd: A quantitative systems approach to identify paracrine mechanisms that locally suppress immune response to Interleukin-12 in the B16 melanoma model. Integr Biol (Camb) 2012, 4:925-936.

81. Hou CH, Chiang YC, Fong YC, Tang CH: WISP-1 increases MMP-2 expression and cell motility in human chondrosarcoma cells. Biochem Pharmacol 2011, 81:1286-1295.

82. Nagai $Y$, Watanabe M, Ishikawa S, Karashima R, Kurashige J, Iwagami S, Iwatsuki M, Baba Y, Imamura Y, Hayashi N, Baba H: Clinical significance of Wnt-induced secreted protein-1 (WISP-1/CCN4) in esophageal squamous cell carcinoma. Anticancer Res 2011, 31:991-997.

83. Kim S, Karin M: Role of TLR2-dependent inflammation in metastatic progression. Ann N Y Acad Sci 2011, 1217:191-206.

84. Freytag J, Wilkins-Port CE, Higgins CE, Carlson JA, Noel A, Foidart JM, Higgins SP, Samarakoon R, Higgins PJ: PAI-1 regulates the invasive phenotype in human cutaneous squamous cell carcinoma. J Oncol 2009, 2009:963209.

85. Czekay RP, Wilkins-Port CE, Higgins SP, Freytag J, Overstreet JM, Klein RM, Higgins CE, Samarakoon R, Higgins PJ: PAI-1: an integrator of cell signaling and migration. Int J Cell Biol 2011, 2011:562481.

86. Xiang B, Wang W, Li W, Li X, Li X, Li G: Differential expression of oxidored nitro domain containing protein 1 (NOR1), in mouse tissues and in normal and cancerous human tissues. Gene 2012, 493:18-26.

87. Zhao Y, Bruemmer D: NR4A orphan nuclear receptors: transcriptional regulators of gene expression in metabolism and vascular biology. Arterioscler Thromb Vasc Biol 2010, 30:1535-1541.

88. Li QX, Ke N, Sundaram R, Wong-Staal F: NR4A1, 2, 3-an orphan nuclear hormone receptor family involved in cell apoptosis and carcinogenesis. Histol Histopathol 2006, 21:533-540.

89. Cho SG, Li D, Tan K, Siwko SK, Liu M: KiSS1 and its G-protein-coupled receptor GPR54 in cancer development and metastasis. Cancer Metastasis Rev 2012, 31:585-591.

90. Liu SC, Bassi DE, Zhang SY, Holoran D, Conti CJ, Klein-Szanto AJ: Overexpression of cyclin D2 is associated with increased in vivo invasiveness of human squamous carcinoma cells. Mol Carcinog 2002, 34:131-139.

91. Rojas P, Cadenas MB, Lin PC, Benavides F, Conti CJ, Rodriguez-Puebla ML: Cyclin D2 and cyclin D3 play opposite roles in mouse skin carcinogenesis. Oncogene 2007, 26:1723-1730.

\section{doi:10.1186/scrt454}

Cite this article as: Koellensperger et al:: Alterations of gene expression and protein synthesis in co-cultured adipose tissue-derived stem cells and squamous cell-carcinoma cells: consequences for clinical applications. Stem Cell Research \& Therapy 2014 5:65. 